\title{
Comparison of MALDI-TOF mass spectrometry with phenotypic methods for identification and characterization of Staphylococcus aureus causing mastitis
}

\author{
Alharbi, A. ${ }^{1,2}$, Al-Dubaib, M. ${ }^{1}$, Elhassan M.A. Saeed ${ }^{1,5}$, Elbehiry, A. ${ }^{3,4^{*}}$ \\ ${ }^{1}$ Department of Veterinary Medicine, College of Agriculture and Veterinary Medicine, Qassim University, Saudi Arabia \\ ${ }^{2}$ Ministry of Environment, Water and Agriculture, Saudi Arabia \\ ${ }^{3}$ Department of Bacteriology, Mycology and Immunology, Faculty of Veterinary Medicine, University of Sadat City, Egypt \\ ${ }^{4}$ Department of Public Health, College of Public Health and Health Informatics, Al Bukayriyah, Qassim University \\ ${ }^{5}$ Department of Microbiology, Faculty of Veterinary Medicine, Khartoum University \\ *Corresponding author: aymanella2007@yahoo.com
}

\section{ARTICLE HISTORY}

Received: 7 January 2021

Revised: 13 February 2021

Accepted: 14 February 2021

Published: 30 April 2021

\begin{abstract}
The emergence of methicillin-resistant Staphylococcus aureus (MRSA) infection is one of the greatest threats to both animal and human health. Our investigation was aimed to identify and differentiate between MRSA and methicillin-sensitive Staphylococcus aureus (MSSA) recovered from mastitic milk using MALDI-TOF mass spectrometry compared with phenotypic methods and studying their susceptibility to various antibiotics. Four hundred milk samples from mastitic animals (cows, sheep, goats, and dromedary camels) were investigated. Phenotypic identification of $S$. aureus was made through MASTASAPH Latex test, STAPH ID 32, and Vitek 2 system. The proteomic characterization of S. aureus was done by MBT. The Kirby Bauer method was accomplished to detect the resistance of $S$. aureus strains to antibiotics. The results of the MASTASAPH Latex test, revealed that $54(46 \%)$ were recognized as $S$. aureus. All S. aureus isolates were identified by MBT with a score of more or equal 2.00 . Several peaks were identified in the mass of $4590 \mathrm{Da}, 4863 \mathrm{Da}$, and $4938 \mathrm{Da}$ for MSSA and in the mass of $2636 \mathrm{Da}$ and 3009 Da for MRSA. The MSP dendrogram demonstrated that the S. aureus isolates were classified into one group with a distance level of less or equal 400 . The percentage of S. aureus resistance against carbenicillin, erythromycin and kanamycin was $94.4 \%, 38.88 \%$, and $33.33 \%$, respectively. In conclusion, S. aureus bacteria are among the key triggers for mastitis in Saudi Arabia. MBT is reported to be not only the rapid tool to identify $S$. aureus but also able to discriminate MRSA from MSSA.
\end{abstract}

Keywords: S. aureus mastitis; MRSA; single peak; PCA; antimicrobial resistance

\section{INTRODUCTION}

Mastitis is one of the common obstacles in various dairy farms in many parts of the world from the investigative, pathogenic, cost-effective, and public health-related viewpoints (Varela-Ortiz et al., 2018). Mastitis has severe economic effects and leads to a decrease in the quality and quantity of milk due to the change in milk composition; the milk volume becomes instable. Furthermore, the fertility of the animal is damaged, which causes an unsystematic estrus cycle and a problem in calving. On the other hand, other costs are incurred due to the need for intervention, herd treatment, and infection control (Rollin et al., 2015; Pumipuntu et al., 2019).

Many types of pathogenic microorganisms can cause mastitis, amounting to at least 137 microorganisms. They include Escherichia coli and Streptococcus agalactiae. However, Staphylococci remain the key factor that causes mastitis in a lot of dairy herds (Sender et al., 2017; Varela-Ortiz et al., 2018).
Many forms of mastitis are caused by various bacteria such as Staphylococcus species. Both Staphylococcus aureus (S. aureus) and coagulase-negative staphylococci (CNS) and are two of the main microorganisms associated with clinical and subclinical mastitis (Elbehiry et al., 2016; Pumipuntu et al., 2019). Staphylococcus includes 49 species and 26 subspecies, divided into two clusters according to their capability to yield coagulase (Taponen et al., 2012; Han et al., 2015). S. aureus is a major cause of mammary infections in dairy animal (Zecconi \& Scali, 2013; Wang et al., 2018). About $10-40 \%$ of mastitis infections are caused by $S$. aureus in China and other countries (Basanisi et al., 2017; Wang et al., 2018). Moreover, this kind of bacteria is highly infectious to humans (Pollitt et al., 2018). Remarkable alterations have befallen in the epidemiology of $S$. aureus over the last few years. For instance, methicillinresistant Staphylococcus aureus, known as MRSA, which was essentially restricted to health facilities, has become an important pathogen in society. This enhances the significance of this pathogen to public health as well as animal health 
(Guimarães et al., 2017). Although S. aureus is a key reason for animals' mastitis, previous studies have shown a lower spread of cow MRSA, indicating that MRSA does not usually accompany mastitis (Hendriksen et al., 2008; Guimarães et al., 2017).

S. aureus mastitis can be analyzed by phenotypic and genotypic methods to offer the most consistent consequences. Phenotypic and genotypic techniques require significant effort and cost. Further, these methods have not yet been used to distinguish between MRSA and MSSA. Differentiation between MRSA and MSSA has been previously studied using different methods (Koivula et al., 2007; Wolters et al., 2010; Elbehiry et al., 2016), especially with the spectral differences (Du et al., 2002; Böhme et al., 2012; Elbehiry et al., 2016). However, slight strong proof has been existed on the application of peptide mass fingerprinting technique (PMFT) as a rapid and accurate method for identifying various $S$. aureus isolates at the species level. According to previous studies (Koivula et al., 2007; Wang et al., 2013; Cantekin et al., 2015; Elbehiry et al., 2016), one of the most prominent boundaries connected to the accurate detection of $S$. aureus is the lack of a precise, prompt, and appropriate tool that has the ability to distinguish the bacterial classes involving this pathogen.

However, almost all molecular methods approximately are effortful and expensive. Therefore, there is still a need for a fast, cost-effective, and accurate method to detect the various microorganisms of infectious diseases. Generally, PMFT, as a creative technique, provides an accurate and quick description of the various microbes and is considered a good step toward the proper management of infectious illnesses in veterinary and medical identification (Sauer et al., 2008; Elbehiry et al., 2016). As a new technology for identifying microorganisms, PMFT depends on the protein structure of the cells of the microbes. Although this technique appeared years ago, only recently did studies show a positive detection of the species in the research laboratory (Emonet et al., 2010; Cherkaoui et al., 2011; Sun et al., 2020). In the last two years, this technology has been used as a common technology for species identification because it is carried out in a short time, nearly one working day (Burckhardt \& Zimmermann, 2011). This technology is characterized by being fast and costeffective provided that there is a quality-managed database of the reference spectra that comprises all the microorganisms. Great endeavors have led to the standard sample arrangement protocols; thus, improved analysis and database tools have emerged (Cherkaoui et al., 2011; Yan et al., 2020). In the current study, the recent methods and the new-generation technologies are compared to the classical methods of bacteria identification.

The failure to treat $S$. aureus-associated mastitis goes back to the long period of treatment, and the infection resulting from $S$. aureus yielding beta-lactamase. In addition, S. aureus causes an abscess rounded by capsules of thick fibers in the mammary gland. This plays a role in the accumulation of antibiotics on the target location, and bacterial destruction is reduced (Basdew \& Laing, 2011; Sađlam et al., 2017). The development of MRSA strains has led to the application of intravenous antibiotics that have the potential for common side effects such as diarrhea, nausea, and headache and less common adverse effects (e.g. hypertension, lactic acidosis, and elevated liver enzymes) (Miller et al., 2020). The ability of S. aureus to form a biofilm also increases its pathogenicity as well as resistance to many antibiotics (Luther et al., 2018). The spread of this kind of bacteria as a species resistant to many antibiotics and causing wide infections is escalating, with minimal treatment options (Goudarzi et al., 2020).

Based on the above facts, this study seeks to shed light on the using of MBT compared with the phenotypic methods for identification and discrimination of both MRSA and MSSA recovered from various dairy farms with a history of mastitis. A further objective was to examine the vulnerability of $S$. aureus strains to antibiotics commonly used to treat $\mathrm{S}$. aureus mastitis.

\section{MATERIALS AND METHODS}

\section{Sample Collection}

In the current study, 400 mastitic milk samples from different animal species ( 100 from cows, 100 from sheep, 100 from goats, and 100 from dromedary camels) of selected farms with a high frequency of $S$. aureus in the Al-Qassim region of KSA. Strict hygienic measures were adopted during the collection of milk samples to avoid contamination via the microorganisms existing in the udder and teats and to avoid the accumulation of microorganisms on the hands of the sample collectors and in the environment.

Before the sample was taken, the ends of the teats were disinfected and washed using ethanol (70\%). The initial milking was disposed of to considerably lower the infection of the teat canal (Quinn et al., 1999). Also, a sterilized universal bottle and well-fitted cups were used. The universal bottle was marked with a long-lasting marker before the process of sampling. To minimize the possibility of contaminating the teat ends while taking the sample, the close teats were firstly sampled and then the far ones (Quinn et al., 1999). Approximately $10 \mathrm{ml}$ of sterile milk was gathered from each quarter utilizing a screw-lidded sterile analysis coded tube. All samples were transported as soon as possible to the Microbiology Laboratory. If direct inoculation wasn't suitable, samples were reserved at $4^{\circ} \mathrm{C}$ until cultivated for isolation within $24 \mathrm{~h}$. Each sample was streaked on blood agar, Mannitol salt agar, Baird-Parker agar (BPA), and MacConkey agar media at $37^{\circ} \mathrm{C}$ for $24 \mathrm{~h}$.

\section{Isolation of S. aureus}

Firstly, all milk samples were streaked on blood agar and then incubated at $37^{\circ} \mathrm{C}$ for $48 \mathrm{~h}$. Based on the roles and regulations of National Mastitis Council (2011), isolation of all samples were carried out. The initial detection of $S$. aureus strains was carried out by the morphological features of the colonies, degree of hemolysis, as well as Gram staining technique. Colonies that appeared as grayish-white, creamy, and/or golden-yellow coloration were recognized as S. aureus. In addition, colonies that showed positive results to catalase and coagulase tests were initially identified as S. aureus. Afterward, a specific medium was used for examination of culture features.

\section{Phenotypic identification of S. aureus}

\section{Catalase test}

This test was predominantly utilized for differentiation between Staphylococci and Streptococci. In brief, 1-2 ml of $\mathrm{H}_{2} \mathrm{O}_{2}$ solution was dispensed into a sterile tube. A sterilized wooden stick was utilized to take numerous colonies of the 18 to $24 \mathrm{~h}$ test bacterium and then immersed in the $\mathrm{H}_{2} \mathrm{O}_{2}$ solution. Positive results were indicated by appearance of bubbles immediately after the addition of $\mathrm{H}_{2} \mathrm{O}_{2}$. 


\section{MASTASAPH Latex test}

This test is a commonly putative technique for distinguishing S. aureus from other Micrococcaceae. S. aureus is recognized to release coagulase, which be able to clot plasma in the gel. This experiment is valuable in distinguishing $S$. aureus from other CNS. An agglutination test (MASTSTAPH) was carried out according to the method described by Macfaddin (2000). Briefly, the MASTASAPH Latex reagent was used to equilibrate room temperature and shaken well. Then, 1 drop of MASTASAPH Latex reagent was added to a circle on the MASTASAPH test card. From overnight culture plate, 2 to 4 colonies were emulsified and spread thoroughly over the circle of the latex cards and the results were then interpreted within 1 minute after gentle shaking the cards.

\section{STAPH ID 32 (API system)}

API Staph is considered a valuable test for rapid identification of Staphylococcal spp. The API Staph ID 32 test strip is composed of 32 capsules, of which (26) capsules encompass dehydrated biochemical agents for colorimetric analyses. The test was implemented and interpreted as stated by the company's instructions (bioMérieux, Lyon, France). In brief, the stored $S$. aureus strains were re-cultured on blood agar. The bacterial suspensions were prepared after one successive day of incubation for all isolates, to a density of $0.5 \mathrm{McF}$ arland in $6 \mathrm{ml}$ of purified water and dispersed into the wells of the strips. Afterword, the prepared strips were incubated at $37^{\circ} \mathrm{C}$ and inspected by naked eye after $24 \mathrm{~h}$. The isolates of $S$. aureus were offered and recognized through Automatic Testing Bacteriology (ATB) Expression and the interpretation of these files was carried out through API laboratory (LAB) software. LAB allows for the likelihood of result detection in a range of $10 \%$ to $100 \%$ (Sampimon et al., 2009).

\section{Vitek 2 system}

In the present research, the Vitek 2 system (ID-Gram Positive Cocci cards, ID-GPC), bioMérieux) was also used for the verification of Staphylococcal species following the instructions of the manufacturing corporation. The ID-GPC card is composed of plastic that encompasses sixty-four wells and is divided into 18 flatulent and 46 well for fluorimetric testing and inhibitory tests that encompass $\mathrm{pH}$ change tests and derivatives to find -oxidases and aminopeptidases. Normally, -oxidases detection substrates are paired with 4methylumbelliferone ( $4 \mathrm{MU})$; substrates for the finding of -oxidases are paired with $(4 \mathrm{MU})$. The twenty-one test substrates are: tyrosine-7AMC, pyroglutamic acid-7AMC, proline-7AMC, phenylalanine-7AMC, lysine-7AMC, threonine7AMC, $\alpha$-glutamic acid-7AMC, histidine-7AMC, aurease (butiloxicarbonyl-Val-Pro-Arg-AMC), arginine-7AMC, alanine7AMC, 4MU-phosphate, 4MU-n-acetyl- $\beta$-d-glucosaminide, $4 \mathrm{MU}-\beta$ - $d$-mannoside, $4 \mathrm{MU}-\beta$ - $d$-glucuronide, $4 \mathrm{MU}-\beta$ - $d$-glucoside, $4 \mathrm{MU}-\beta$ - $d$-galactoside, $4 \mathrm{MU}-\alpha-d-\mathrm{N}$-acetylneuraminic acid, $4 \mathrm{MU}-\alpha-\mathrm{d}$-glucoside, $4 \mathrm{MU}-\alpha-\mathrm{d}$-galactoside, and $4 \mathrm{MU}-\alpha-\mathrm{I}-$ arabinofuranoside. Moreover, the card encompasses sixteen fermentation tests, which are Salicin, $\mathrm{N}$-acetyl-glucosamine, I-arabinose, lactose, glycerol, d-xylose, d-trehalose, d-sorbitol, d-raffinose, d-melibiose, d-mannitol, d-maltose, d-glucose, d-galactose, arbutine, and amygdaline), two decarboxylase tests (ornithine and arginine), and other six other tests $(6.5 \%$ $\mathrm{NaCl}$, polymyxin B sulfate, novobiocin, optochin, pyruvate, and urease). In brief, 2-3 fresh pure colonies were transferred by a sterile swab into a sterilized plastic test tube containing $3.0 \mathrm{~mL}$ of sterile saline. The tube was then vortexed and the turbidity was adjusted (GP: 0.50-0.63) using DensiChek ${ }^{\mathrm{TM}}$. The results were interpreted according to the identiûcation levels of the Vitek 2 system (Table 1 ).

\section{Cefoxitin disc diffusion technique for identification of MRSA}

According to CLSI (2009) standards, cefoxitin disc diffusion method was achieved for differentiation between MRSA and MSSA. Briefly, the bacterial suspension was adjusted 10.5 McFarland) and then scattered on the Mueller-Hinton agar plates. Cefoxitin discs $(30 \mu \mathrm{g})$ were inserted in the plates and then all plates were incubated for $18-24 \mathrm{~h}$ at $35^{\circ} \mathrm{C}$. the results were interpreted by measuring the inhibition zone (susceptible, $\geq 22 \mathrm{~mm}$; resistant, $\leq 21 \mathrm{~mm}$ ). This test was performed twice to obtain accurate results.

\section{Proteomic identification of $S$. aureus isolates}

\section{Ethanol/Formic Acid Extraction protocol}

To precisely detect all S. aureus strains, the PMFT (MALDI Biotyper, Bruker Daltonics, Germany) was used. All samples were analyzed using FlexControl software with Compass Flex Series version 1.3 software. It was determined that the isolates with score of $\geq 2.000$ are set as species-level identification, whereas the isolates with the score of 1.70 to 1.99 are set as genus-level identification. Full-extraction controls (Ethanol/Formic Acid Extraction protocol) were accomplished as stated by Barreiro et al. (2010). In brief, all samples were prepared by culturing on blood agar, then incubated for $18-24$ hours at $37^{\circ} \mathrm{C}$.

For each sample, 1-2 fresh colony were transmitted to a clean Eppendorf tube and thoroughly mixed in $300 \mu \mathrm{l}$ of distilled water. Nine hundred $\mu \mathrm{l}$ of pure ethanol was then added. The contents were prudently mixed, and then the centrifugation was carried out for all tubes for 2 minutes at $13,000 \mathrm{rpm}$. The pellet of each tube was left to dry in air after removal of the supernatant. The pellet was then blended with $50 \mu \mathrm{l}$ of formic acid (70\%) before the addition of an equal quantity of acetonitrile. Centrifugation of the mixture was then carried out for a couple of minutes at $13,000 \mathrm{rpm}$ and then $1 \mu \mathrm{l}$ of the supernatant was inoculated onto a target plate and permitted to dry for 5 minutes at $25^{\circ} \mathrm{C}$. Subsequently, each isolate was covered with one $\mu$ l of matrix solution ( $\alpha$-cyano- 4 hydroxy-cinnamic acid, HCCA). Finally, the target plate was inserted in the MBT device for programmed running and data analysis. Escherichia coli was used as Bacterial test standard (BTS) throughout the experiment.

\section{Data analysis, Discrimination, and Clustering}

Within the range from 0 to 3 , the score value of the unidentified spectrum was pinpointed through the concord between the anonymous spectrum and the well-known spectra kept in the reference library. The species and genus level are foreseeable in the range from 2.00 to 2.29 and 1.700 to 1.999 , respectively. Moreover, a score of 0.00 to 1.69 indicates that the evidence of identification is unreliable.

Table 1. Identification levels of the Vitek 2 system

\begin{tabular}{lcc}
\hline $\begin{array}{l}\text { ID Massage } \\
\text { Confidence Level }\end{array}$ & Choices & \% of identification probability \\
\hline $\begin{array}{l}\text { Excellent } \\
\text { Very Good }\end{array}$ & 1 & 96 to 99 \\
Good & 1 & 93 to 95 \\
Acceptable & 1 & 89 to 92 \\
Low Discrimination & 1 & 85 to 88
\end{tabular}


The different spectra made by the MBT software were detected in an $\mathrm{m} / \mathrm{z}$ range from 2,000 Da to 20,000 Da. PCA and SPI were generated by the software to differentiate between MRSA and MSSA isolates. As per the MBT library, which contains more than 7000 bacterial and fungal sub-species, a dendrogram was also brought about from the (MSP) data set. The MSP dendrogram was brought about as per the assessment of the key spectra of the identified species. Primarily, the main spectra of the MBT taxonomy were matched with the resultant spectra in a cross-wise matrix.

\section{Susceptibility of $\boldsymbol{S}$. aureus strains to various antimicrobial agents}

The Kirby-Bauer method was accomplished to detect the degree of sensitivity and resistance of $S$. aureus strains against various antimicrobial agents. This examination was carried out and the results were registered in keeping with the approvals and measures of the National Committee of CLSI (2016). As shown in Table 2, the following disks (Company, Mast Diagnostika, Germany) were applied in our current study: clindamycin $(2 \mu \mathrm{g})$, erythromycin $(10 \mu \mathrm{g})$, cefoxitin $(30 \mu \mathrm{g})$, kanamycin $(30 \mu \mathrm{g})$, gentamicin $(120 \mu \mathrm{g})$, neomycin (30 $\mu \mathrm{g})$, carbenicillin $(100 \mu \mathrm{g})$, ciprofloxacin $(5 \mu \mathrm{g})$, and chloramphenicol (10 $\mu \mathrm{g})$.

In brief, all isolates were incubated at $37^{\circ} \mathrm{C}$ for $24 \mathrm{~h}$ to obtain fresh colonies. Then, 3-4 of these colonies were inoculated via a disposable inoculator loop onto a sterile tube containing $5 \mathrm{ml}$ of sodium chloride $(0.9 \%)$ and mixed carefully. The turbidity of the growing culture was equilibrated with $\mathrm{NaCl}(0.9 \%)$ using Sensititre (TREK Diagnostic Systems, Ashford, Kent, England) to obtain turbidity optically comparable to that of the 0.5 McFarland standards (ca $1 \times 10^{8}$ $\mathrm{CFU} / \mathrm{mL}$ ). Within 15 minutes after adjustment of the turbidity of the suspension, a clean cotton swab was dipped into the suspension and then firmly pressed against the inner side of the test tube, and then the swab was rotated to discard the excess liquid. After squeezing, the swab was speckled onto the whole surface of a Mueller-Hinton agar plate (Cat. No.: MDM 355) using a sterile swab 3 times. The Mueller-

Table 2. Zone diameter interpretative references (NCCLS, 2013) for different antimicrobial drugs against $S$. aureus strains

\begin{tabular}{lccc}
\hline & & \multicolumn{2}{c}{ Zone diameter of S. aureus $(\mathrm{mm})$} \\
\cline { 2 - 4 } Antimicrobial drug & Conc. $(\mu \mathrm{g})$ & $\mathrm{R}$ & $\mathrm{S}$ \\
\hline Clindamycin & & $\leq 14$ & $\geq 21$ \\
Erythromycin & 2 & $\leq 13$ & $\geq 23$ \\
Cefoxitin & 10 & $\leq 21$ & $\geq 22$ \\
Kanamycin & 30 & $\leq 13$ & $\geq 18$ \\
Gentamicin & 30 & $\leq 19$ & $\geq 27$ \\
Neomycin & 120 & $\leq 16$ & $\geq 26$ \\
Carbenicillin & 30 & $\leq 23$ & $\geq 29$ \\
Ciprofloxacin & 100 & $\leq 15$ & $\geq 21$ \\
Chloramphenicol & 5 & $\leq 12$ & $\geq 18$ \\
\hline
\end{tabular}

Hinton plate was rotated about 60 degrees after each use to confirm good spreading of the inoculum on the plate's surface.

Finally, the antimicrobial disks were directly pressed down onto the plates using sterilized forceps. All disks were incubated at $37^{\circ} \mathrm{C}$ for a couple of days. The zone's diameter was measured using a cylinder after incubation, and the results were interpreted in millimeters. Generally, no more than 6 disks were placed on each plate to prevent the inhibition zone from overlapping and causing a potential mistake in the measurement.

\section{RESULTS}

\section{Preliminary identification of $S$. aureus isolates}

S. aureus isolates were initially detected by colony morphology, degree of hemolysis, and the Gram staining technique. Colonies with a creamy or yellow color that gave positive results in the catalase test, and that also showed both complete and incomplete degrees of hemolysis, were recognized as Staphylococcus. Out of 400 milk samples involved in the current investigation, a total of $120(30 \%)$ isolates of Staphylococcus were isolated. As can be seen in Table 3, 12 $(10 \%)$ of these isolates were recovered from camels, $48(40 \%)$ from cows, 28 (23.3\%) from sheep, and 32 (26.6\%) from goats. The positive results of the MASTASAPH Latex test were interpreted in 54 (45\%) of 120 bacterial isolates, recognized as $S$. aureus, whereas the other 66 strains were recognized as CNS (16 S. chromogens strains, $11 \mathrm{~S}$. haemolyticus strains, $24 \mathrm{~S}$. epidermidis strains, and 15 S. saprophyticus strains). For further analysis, the preliminary identified isolates were deposited in Cryobank vials at $-20^{\circ} \mathrm{C}$.

\section{Biochemical analysis of $\boldsymbol{S}$. aureus strains}

The Vitek 2 Compact system and API system (Staph ID 32 API system) were used as phenotypic techniques for the detection of $S$. aureus. The positive results for the Vitek 2 Compact system were interpreted in $51(94.44 \%)$ of 54 S. aureus isolates, whereas the other 3 strains were recognized as CNS. Based on the results of the Staph ID 32 API system, 48 (88.89\%) strains were properly recognized as $S$. aureus, whereas the other 6 strains were recognized as CNS.

Based on our findings, 54 isolates of $S$. aureus were assessed by various methods for phenotypic identification. All S. aureus isolates were correctly recognized by the MASTASAPH Latex test, $94.47 \%$ of $S$. aureus strains were properly recognized by the Vitek 2 Compact system, and $88.89 \%$ of $S$. aureus isolates were properly recognized by the Staph ID 32 system. From these results, it appears that the MASTASAPH Latex test is considered a good tool for phenotypic identification of various strains of $S$. aureus.

\section{Standard detection of MRSA strains}

A modified Kirby-Bauer method (agar disk diffusion) was carried out to test the isolates of $S$. aureus for their resistance

Table 3. Overall number of samples, number of positive Staphylococcus, and percentage (\%) of positive samples

\begin{tabular}{lcccc}
\hline $\begin{array}{l}\text { Animal } \\
\text { species }\end{array}$ & $\begin{array}{c}\text { No. of } \\
\text { samples }\end{array}$ & $\begin{array}{c}\text { No. of positive } \\
\text { Staphylococci }\end{array}$ & $\begin{array}{c}\text { \% of positive } \\
\text { Staphylococci }\end{array}$ & $\begin{array}{c}\text { No. of positive } \\
\text { S. aureus }\end{array}$ \\
\hline Camels & 100 & 12 & $12 \%$ & 7 \\
Cows & 100 & 48 & $48 \%$ & 22 \\
Sheep & 100 & 28 & $28 \%$ & 11 \\
Goats & 100 & 32 & $32 \%$ & 14 \\
Total & $\mathbf{4 0 0}$ & $\mathbf{1 2 0}$ & $\mathbf{3 0 \%}$ & $\mathbf{3 9}$ \\
\hline
\end{tabular}


to methicillin based on the guidelines recommended by NCCLS. A cefoxitin disk $(30 \mu \mathrm{g})$ was used as well as a MullerHinton agar comprising $4 \%$ of $\mathrm{NaCl}$ were used in the current investigation. The inhibition zone was measured after incubation at $37^{\circ} \mathrm{C}$ for $24 \mathrm{~h}$. To calculate the occurrence of the MRSA stains recovered from all clinical samples, the total number of MRSA strains was divided by the total number of isolated S. aureus strains. Out of $54 \mathrm{~S}$. aureus isolates, 17 $(37.7 \%)$ strains presented a $\leq 21 \mathrm{~mm}$ inhibition zone for cefoxitin. Depending on the procedures of the Clinical Laboratory Standard Institute (CLSI), they were classified as Methicillin-Resistant Staphylococcus Aureus (MRSA).

\section{Peptide Mass fingerprinting identification}

In the current investigation, the isolated bacteria were examined by MBT and the resultant spectra were paralleled with the stored spectra in the MBT database. A typical exploration of several $S$. aureus strains recovered from mastitic samples was illustrated by the Compass software of Microflex LT. Based on our results, approximately 20 protuberant ion peaks were observed in the original bands from the zone ranging from 3,000 to 10,000 Daltons (Da) (Figure 1), and strong signals were demonstrated between 6500 and 7000 Da (Figure 2), which coordinated with 3 reference isolates of MRSA stored in the Compass software library (S. aureus ATCC 33591 THL, S. aureus DSM 3463, and S. aureus DSM 20232) and 5 reference strains of MSSA (S. aureus ATCC 29213, S. aureus ATCC 33862, S. aureus DSM 20231, S. aureus DSM 346, and S. aureus DSM 799).

In the current analysis, 40 MSSA and 14 MRSA isolates were properly recognized, with a log score fluctuating from 2300 to 3000 for 6 strains of MSSA and 2 strains of MRSA; 34 MSSA strains and 12 MRSA strains were appropriately documented with a log value fluctuating from 2.00 to 2.29 . However, zero MSSA and MRSA strains were detected in score values from 1.7 to 1.99. Both MSSA and MRSA strains were detected by corresponding their spectra with the MBT database, which contains more than 300 strains of 16 genera from the ATCC and German Collection of Microorganisms and Cell Cultures GmbH (DSMZ).
According to the single peak analysis of various mass areas, frequent dissimilarities were recognized to distinguish between MSSA and MRSA strains. We observed many single peak signals within the range of 2636 to 4938 $\mathrm{Da}$, which revealed numerous variations of intensities between the identified strains of MSSA and MRSA. Thus, the single peak represents a significant tool to distinguish between MRSA and MSSA. The specific results were enlarged into the area of approximately $4590 \mathrm{Da}, 4863 \mathrm{Da}$, and 4938 $\mathrm{Da}$, consistently. In such cases, the single peaks of attention exhibited several differentiations in intensity among MRSA and MSSA. A strong intensity of peaks was detected in MSSA (green color) in the mass of $4590 \mathrm{Da}, 4863 \mathrm{Da}$, and $4938 \mathrm{Da}$ (Figure 3) and was absent in MRSA (red color). In contrast, greater peaks of intensity were identified in MRSA (red color) in the mass of $2636 \mathrm{Da}$ and $3009 \mathrm{Da}$ (Figure 4) and were absent in MSSA (green color).

In addition, the PCA represents a supplementary calculated tool extracted from the Compass software of the MBT for analyzing data sets to illustrate the degree of resemblance and variety of various spectra of the protein profile. Likewise, PCA reduces the variances of a complex dataset, as stated by the different algebraic assessments. Several spectral proteins for MSSA and MRSA isolates were established in three-dimensional (3d) PCA in Figure 5. Every spectrum was represented via dot and the various colors demonstrate the reflected group contribution in which every dot was represented by one spectrum of the protein side view.

The cluster outlook of the 3d PCA illustrated that the majority of peaks for all strains of $S$. aureus were strictly correlated and harmonized (Figure 6). Regarding PCA calculation sets, every single peak may perhaps develop loading values derived from the PC calculation. In our investigation, every signal was identified with loading 1 , loading 2, and loading 3 values resulting from the calculation of PC1, PC2, and PC3. In brief, the influences of the three PCs (PC1, $\mathrm{PC2}$, and $\mathrm{PC} 3$ ) in generating the side view in a proportion plot of the explained variance were approximately $27 \%, 18 \%$, and $10 \%$ for S. aureus (Figure 7 ).

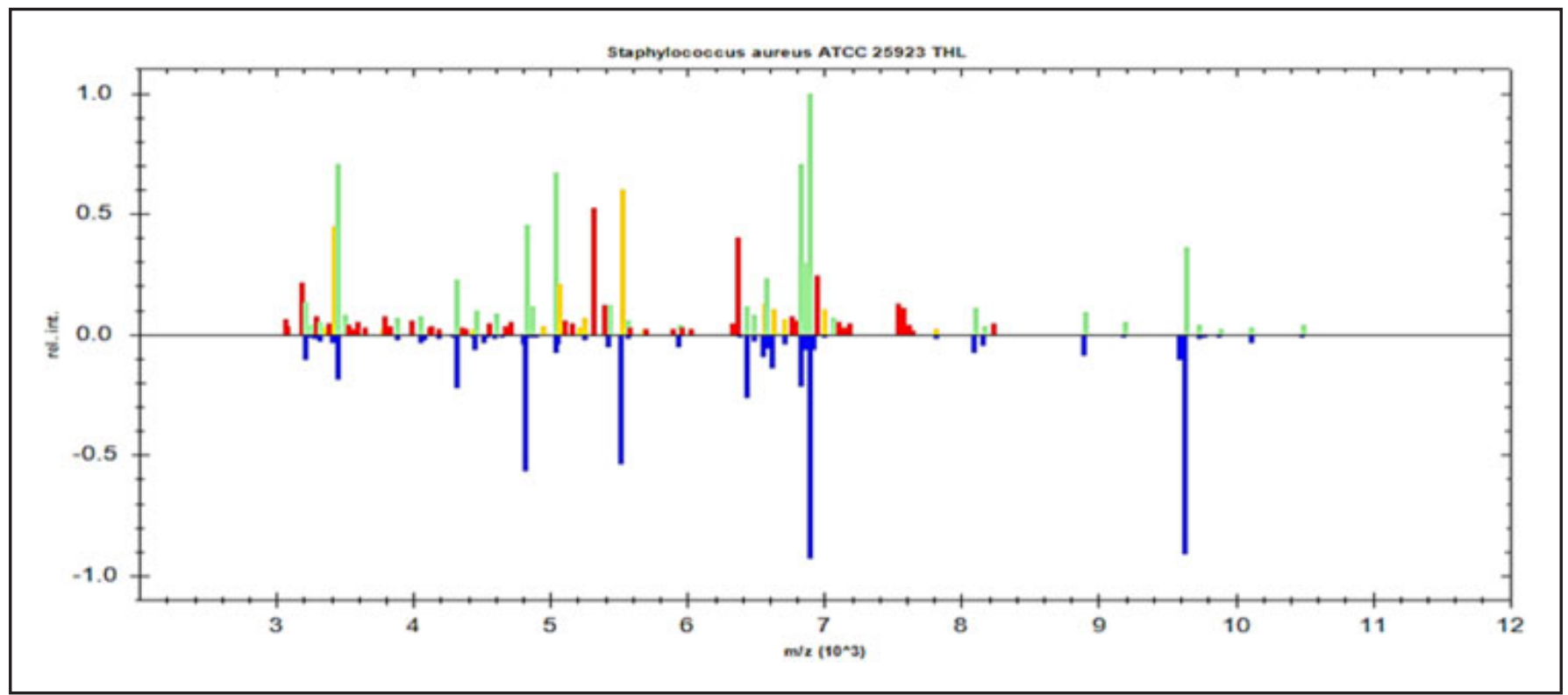

Figure 1. Evaluation of spectral protein profiles of S. aureus recovered from mastitic samples with S. aureus ATCC 25923 as a reference strain stored in the Compass Satellite software. The blue color in the lower part means the stored spectra in the library of the Compass software that was used for matching the pattern; the green color in the upper part of the spectra means excellently matched peaks, whereas the red and yellow colors mean mismatched and intermediate peaks, respectively. 


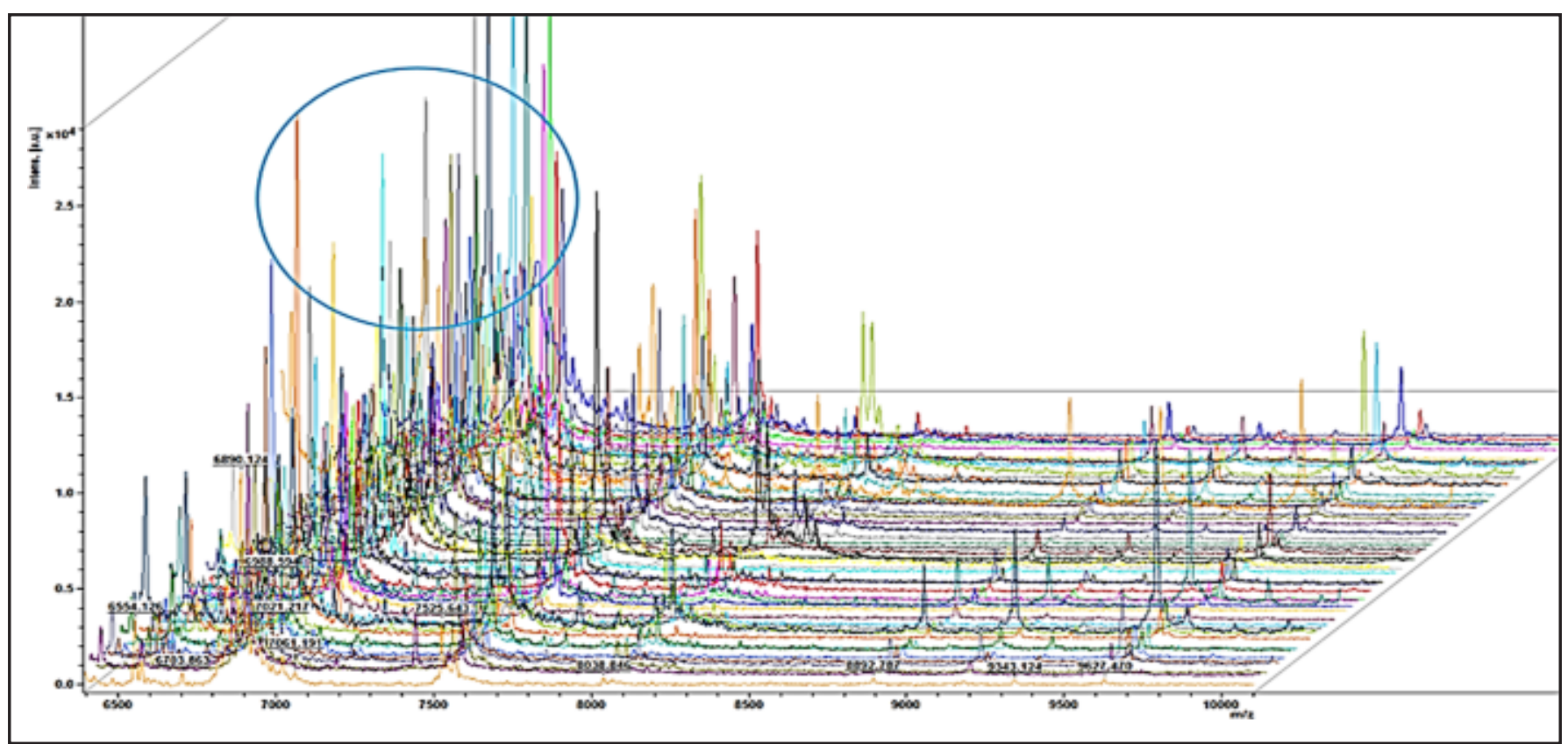

Figure 2. Higher peak intensities of 54 S. aureus strains recovered from milk samples were concentrated between 6,500 and 7,000 Da.

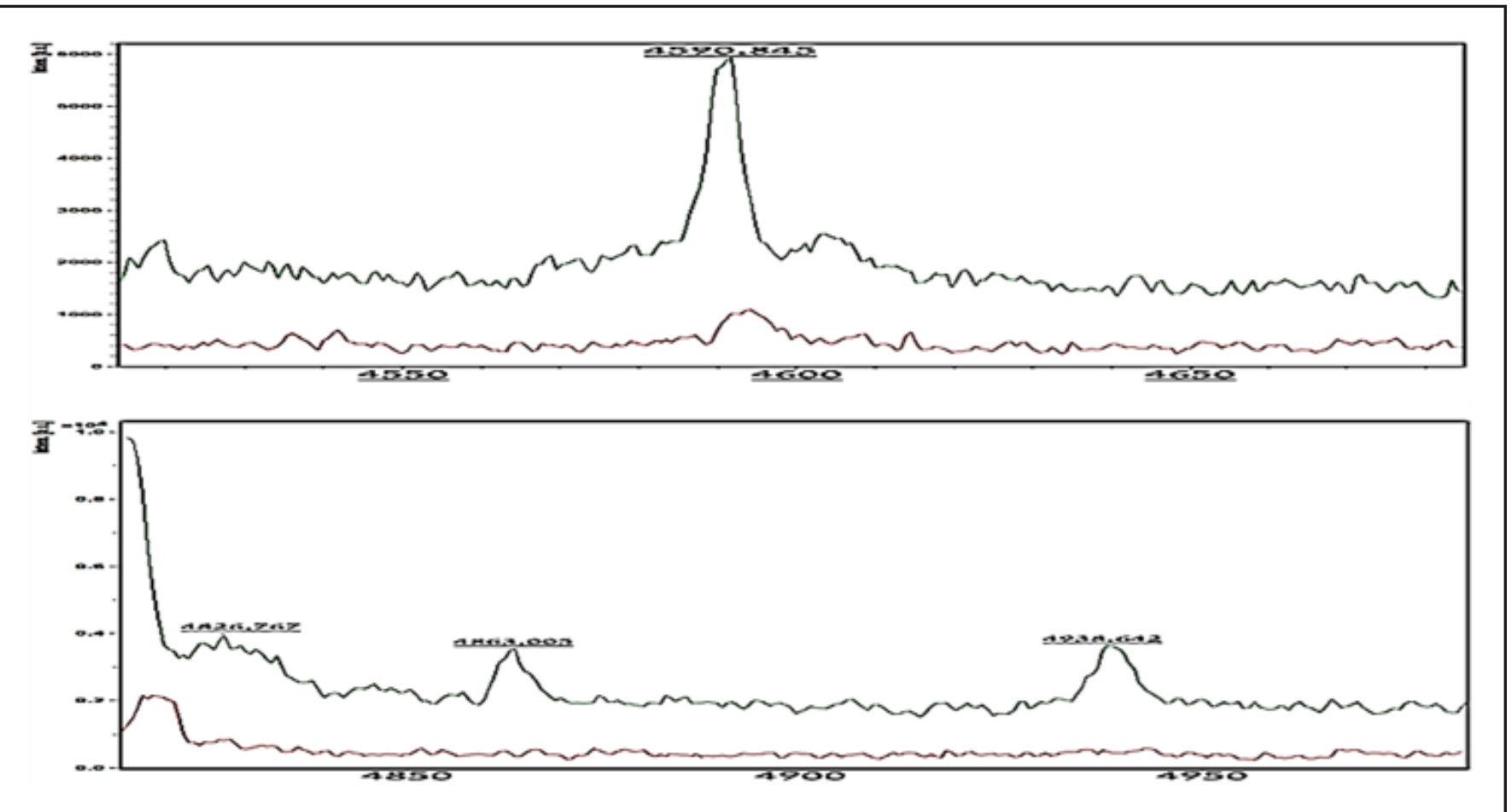

Figure 3. Single peak intensities (4590 Da, $4826 \mathrm{Da}, 4863 \mathrm{Da}, 4938 \mathrm{Da}$ ) were detected in MSSA (green color), while they were absent in MRSA (red color).

A real gel image was created by the Compass software programmed in the MBT for illustration of the protein profile for 54 identified isolates of MRSA. As can be seen in Figure 8 , the spectra were distributed in the range from 3,000 Da to $10,000 \mathrm{Da}$ with strong peaks demonstrated between 3,000 and 10,000 Da. To clarify whether the Compass software program can differentiate the clonally associated strains, bands from 54 strains of both MRSA and MSSA were investigated as described above. Figure 9 shows the MSP dendrogram for 54 isolates of $S$. aureus. Based on our results, the created dendrogram revealed that the evaluated $S$. aureus strains were strictly associated with 8 reference strains of S. aureus. As seen from Table 4, 11 strains were matched with S. aureus spp. aureus DSM 20231T DSM, 12 strains were matched with $S$. aureus spp. aureus DSM 346 DSM, 13 strains were matched with S. aureus ATCC 29213 THL, 3 strains were matched with S. aureus spp. aureus DSM 799 DSM, 1 strain was matched with S. aureus ATCC 33591 THL, 10 strains were matched with S. aureus spp. aureus DSM 3463 DSM, 1 strain was matched with S. aureus ATCC 33862 THL, and 3 strains 


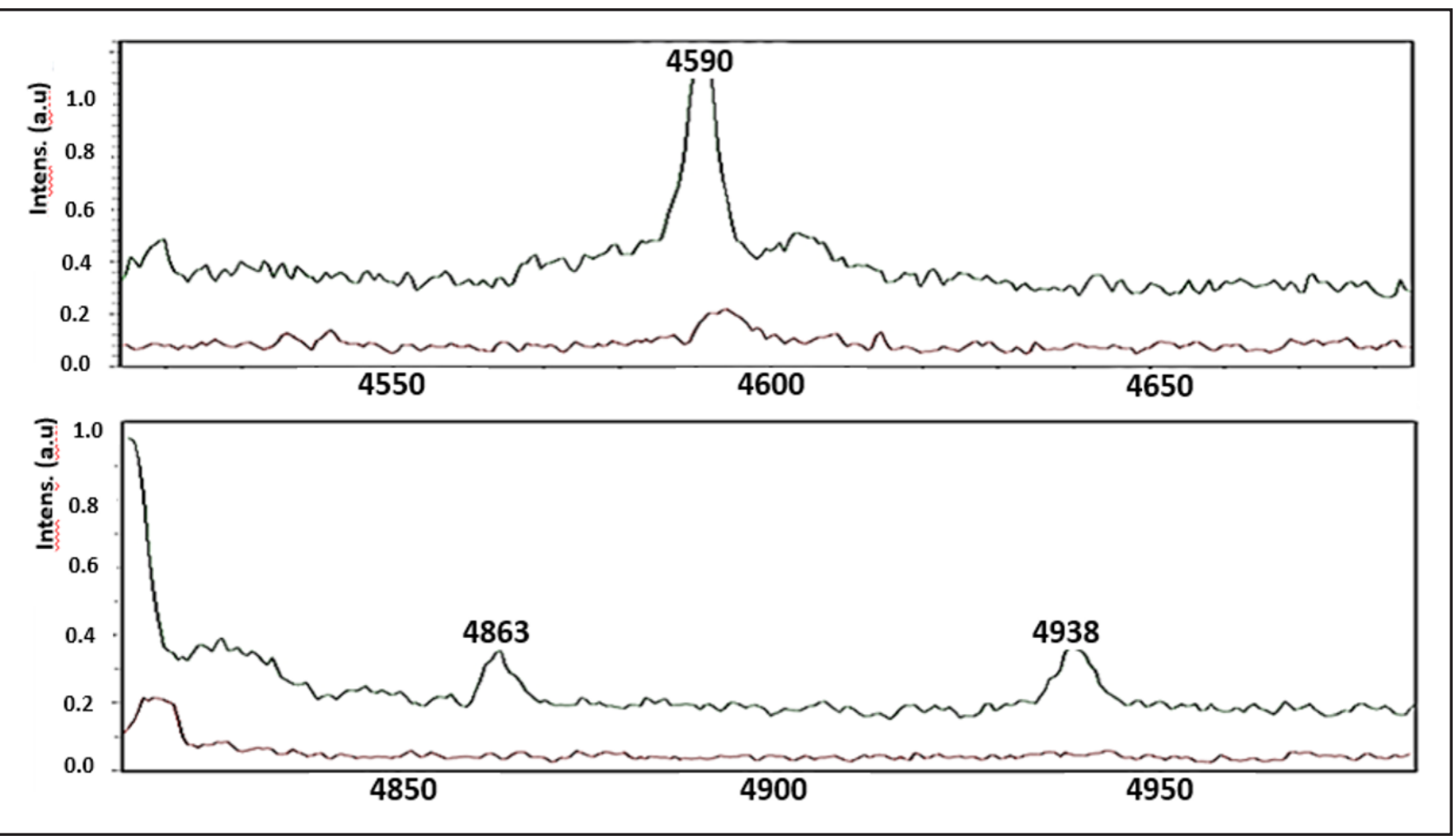

Figure 4. Single peak intensities (2636 Da, $3009 \mathrm{Da})$ were discovered in MRSA (red color), while they were absent in MSSA (green color).

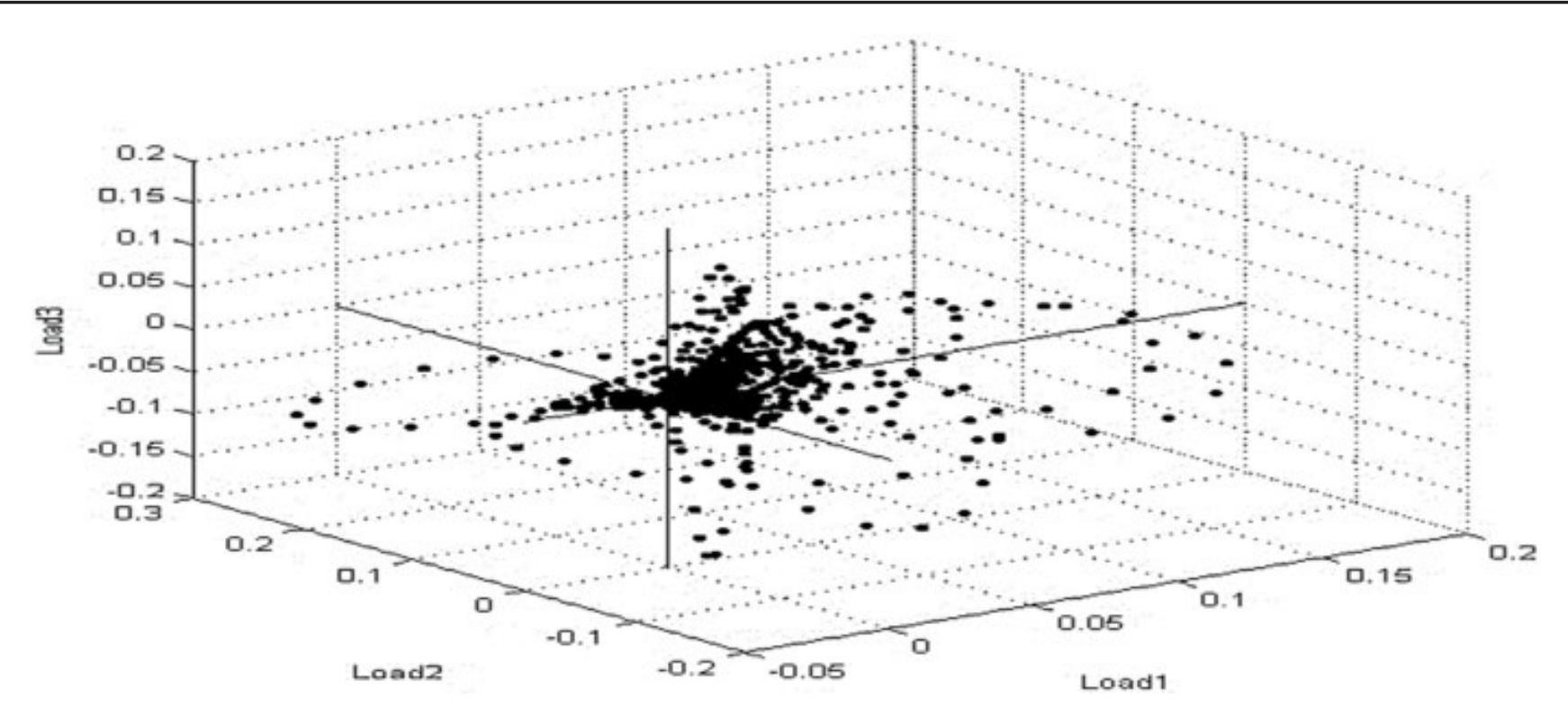

Figure 5. PCA dimensional image illustrating several spectra for S. aureus isolate recovered from mastitic samples. Each spot refers to the strength of single signals. The signa were altered up to the loading value consistent with loading 1 , loading 2, and loading 3 .

were matched with S. aureus spp. aureus DSM 20232 DSM. The results of the MSP dendrogram presented a strong relation among the isolates of $S$. aureus with certain $S$. aureus reference strains, particularly ATCC S. aureus 33591, ATCC S. aureus 29213, ATCC S. aureus 33862, and DSM S. aureus 799.

According to the interpreted results in Table 5, comparing the application PMFT with other conventional methods, it is clear that the PMFT was able to identify S. aureus and other
CNS by $100 \%$. In contrast, the other conventional methods were able to identify $S$. aureus and CNS at varying rates, ranging from $94 \%$ to $73 \%$. Also, the use of MASTASAPH Latex was able to distinguish between S. aureus and other CNS by $100 \%$.

Susceptibility of $S$. aureus strains to various antimicrobial agents Our results were disclosed in keeping with the procedures of the CLSI. An antimicrobial susceptibility test for 54 S. aureus 


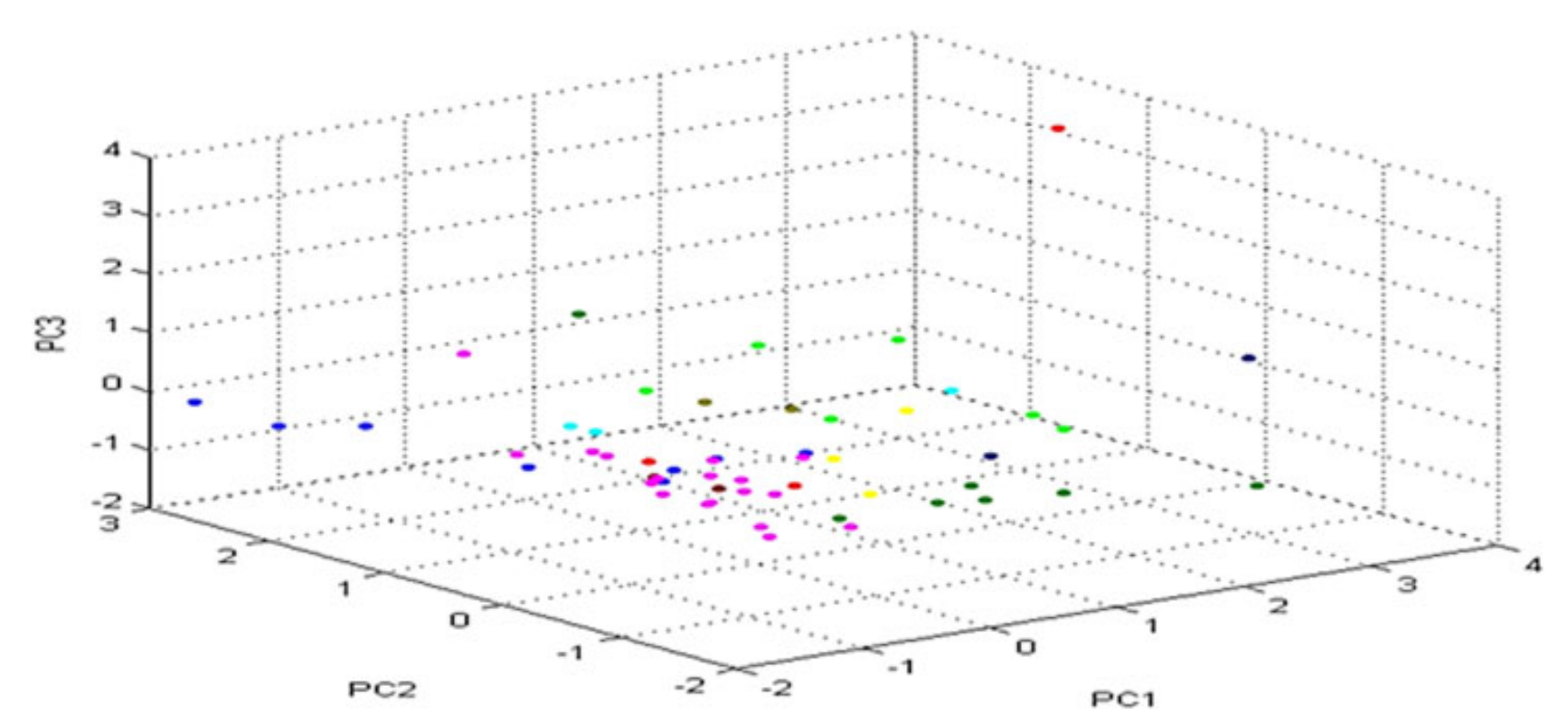

Figure 6. The cluster view of the 3d PCA for nearly all strains of S. aureus (except tw strains) was classified as one group (strictly correlated and harmonized).

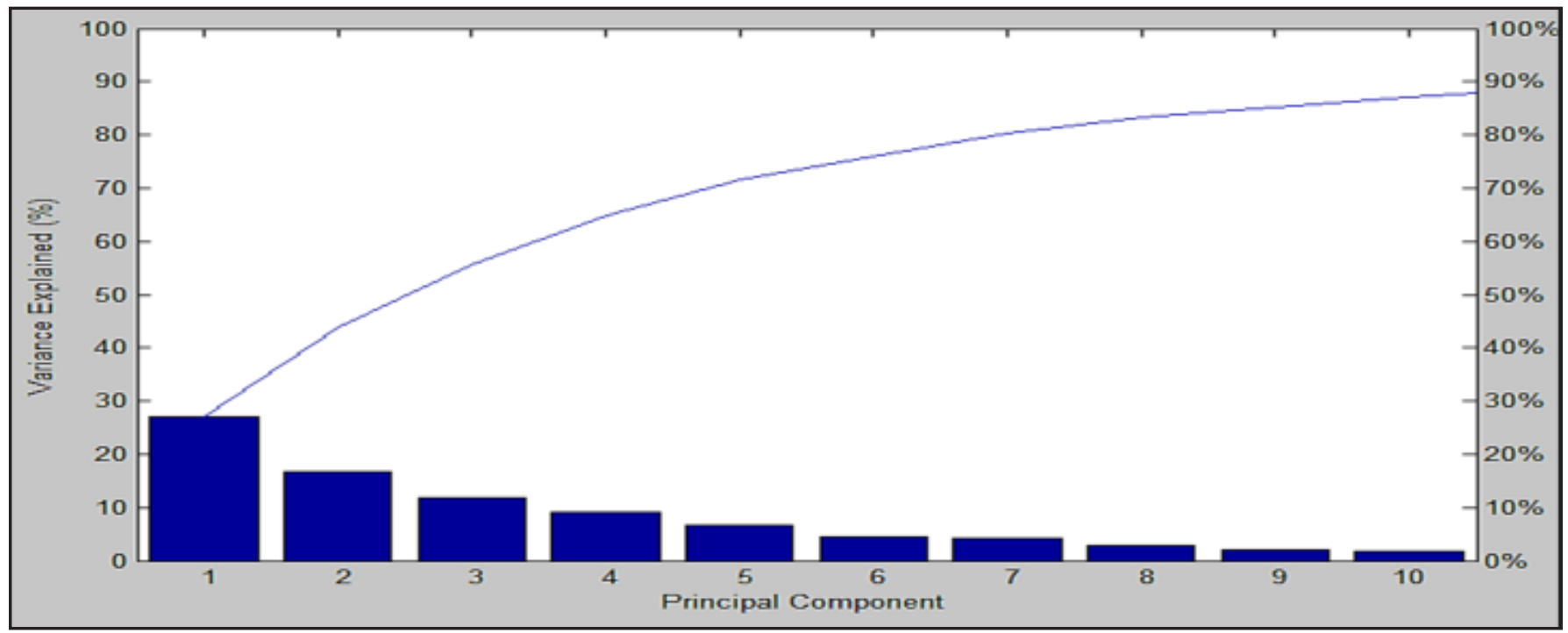

Figure 7. The effect of PCs on the grouping description in the conspiracy of percentage illuminated differences of PC for all strains of $S$. aureus recovered from mastitic samples.

Table 4. The rate of identified S. aureus strains recovered from mastitic milk samples that matched with 8 reference strains of $S$. aureus stored in the MBT library

\begin{tabular}{cl}
\hline $\begin{array}{c}\text { No. of identified } \\
\text { strains }\end{array}$ & Matched reference strains in Bruker library \\
\hline 12 & S. aureus spp. aureus DSM 346 DSM \\
3 & S. aureus spp. aureus DSM 799 DSM \\
10 & S. aureus spp. aureus DSM 3463 DSM \\
1 & S. aureus ATCC 33862 THL \\
3 & S. aureus spp. aureus DSM 20232 DSM \\
11 & S. aureus spp. aureus DSM 20231T DSM \\
1 & S. aureus ATCC 33591 THL \\
13 & S. aureus ATCC 29213 THL
\end{tabular}

strains exhibited that $94 \%(51 / 54), 39 \%(21 / 54), 33 \%(18 / 54)$, $31 \%(17 / 54) 31 \%(17 / 54)$, and $24 \%(12 / 54)$ were resistant to carbenicillin, erythromycin, Kanamycin, cefoxitin, ciprofloxacin and neomycin, respectively. In addition, 72\% (39/54), 81\% $(44 / 54)$, and $94 \%(51 / 54)$ of the tested strains were positively affected by chloramphenicol, gentamicin and clindamycin, respectively. Details on the percentage of resistant and susceptibility of the $S$. aureus strains against various antibiotics are revealed in Table 6 .

\section{DISCUSSION}

S. aureus remains one of the most important complex microbes causing mastitis in various animal farms, thereby creating constant headaches for breeders worldwide due to the 


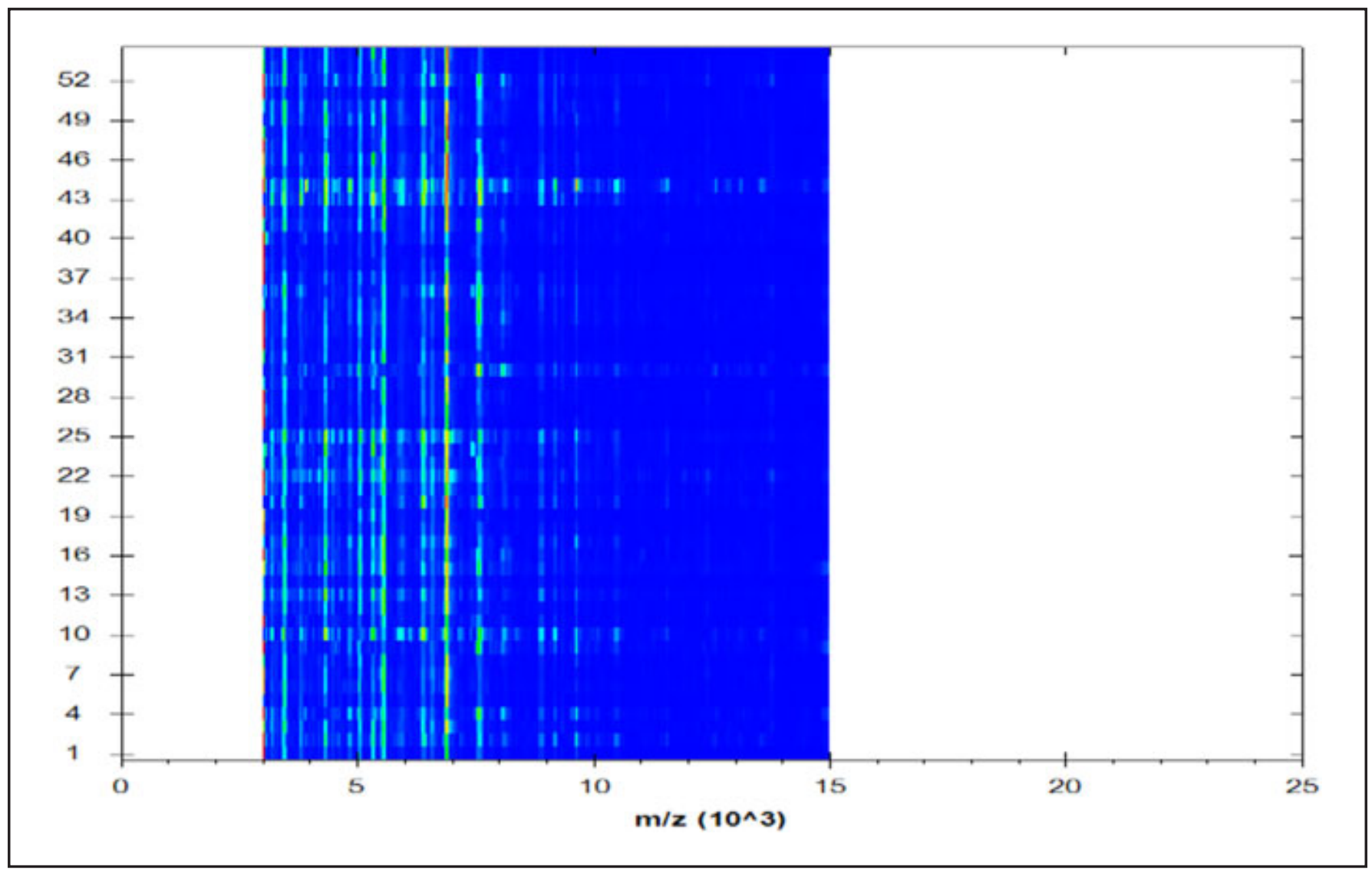

Figure 8. Spectra gel view of protein for 54 MRSA and MSSA strains. The yelllow dots are the gathering of various protein spectra with different insides.

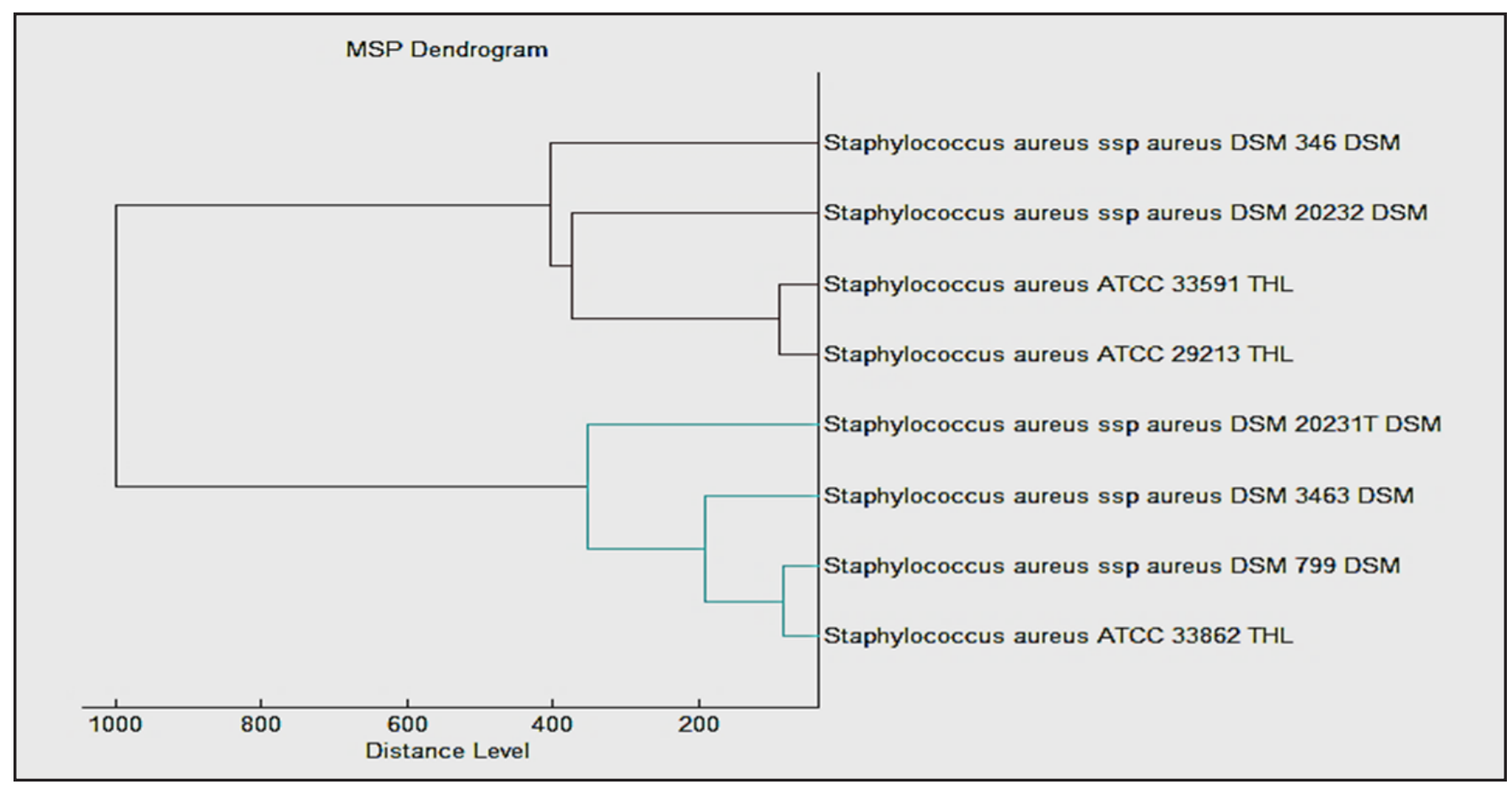

Figure 9. MSP dendrogram for 54 isolates of S. aureus matched with 8 reference strains of S. aureus stored in the Bruker library. 
Table 5. Comparison between PMFT and phenotypic method for identification of S. aureus and other types of Staphylococcus species from different milk samples

\begin{tabular}{|c|c|c|c|c|c|}
\hline \multirow{2}{*}{ Species } & \multirow{2}{*}{ No. of isolates } & \multicolumn{3}{|c|}{ Phenotypic identification } & \multirow{2}{*}{ PMFT } \\
\hline & & API ID system & Vitek 2 system & MASTASAPH Latex & \\
\hline S. aureus & 54 & $89 \%$ & $94 \%$ & $100 \%$ & $100 \%$ \\
\hline S. chromogens & 16 & $75 \%$ & $87.5 \%$ & $0 \%$ & $100 \%$ \\
\hline S. haemolyticus & 11 & $73 \%$ & $91 \%$ & $0 \%$ & $100 \%$ \\
\hline S. epidermidis & 24 & $79 \%$ & 87.5 & $0 \%$ & $100 \%$ \\
\hline S. saprophyticus & 15 & $73 \%$ & $93 \%$ & $0 \%$ & $100 \%$ \\
\hline
\end{tabular}

Table 6. Degree of resistance and susceptibility of identified S. aureus strains against various antibiotics

\begin{tabular}{|c|c|c|c|c|}
\hline \multirow{3}{*}{ Drug class } & \multicolumn{4}{|c|}{ S. aureus } \\
\hline & \multicolumn{2}{|c|}{ Resistant } & \multicolumn{2}{|c|}{ Sensitive } \\
\hline & No. & $\%$ & No. & $\%$ \\
\hline Chloramphenicol & 5 & $9.25 \%$ & 39 & $72.22 \%$ \\
\hline Gentamicin & 6 & $11.11 \%$ & 44 & $81.48 \%$ \\
\hline Carbenicillin & 51 & $94.4 \%$ & 1 & $1.85 \%$ \\
\hline Erythromycin & 21 & $38.88 \%$ & 32 & $59.25 \%$ \\
\hline Clindamycin & 2 & $3.7 \%$ & 51 & $94.44 \%$ \\
\hline Kanamycin & 18 & $33.33 \%$ & 36 & $66.66 \%$ \\
\hline Ciprofloxacin & 17 & $31.4 \%$ & 31 & $57.40 \%$ \\
\hline Neomycin & 13 & $24.07 \%$ & 5 & $9.25 \%$ \\
\hline Cefoxitin & 17 & $31 \%$ & 37 & $69 \%$ \\
\hline
\end{tabular}

resulting economic problems it causes, up to the eradication of infected animals from the herd. Because the milk produced from infected animals is contaminated with $S$. aureus, it may have a significant harmful effect on human health (Li et al., 2017). It is already known that this bacterium is resistant to a very large number of antibiotics used on dairy farms, which represents a clear threat in the process of controlling this microbe (Barlow, 2009).

Because determining the type of microbe causing mastitis, as well as the methods used in early diagnosis, are important to the process of controlling disease in different animal farms, it is necessary to find a quick and effective way to identify the microbes that cause mastitis, so as to create a successful treatment process (El Behiry et al., 2012; Deb et al., 2013). For many years, genetic and other traditional methods have been considered among the most successful methods in the process of diagnosing the microorganisms causing mastitis, but these methods have many drawbacks, such as the long time spent on diagnosis as well as the high cost and the need for specialists trained in these techniques; additionally, false results may be detected (Bizzini et al., 2010; Schröttner et al., 2014).

From this perspective, the initial goal of the current investigation was to compare phenotypic methods (MASTAST Latex, STAPH ID 32, Vitek-2) with PMFT as techniques to identify the level of $S$. aureus species in various dairy animals suffering from intra-mammary infection. The current study showed that the number of $S$. aureus from 400 samples from various dairy animals infected with mastitis was $13.5 \%$ (54 isolates), through isolating the strains in the laboratory using fundamental protocols (e.g., color of colonies, colony morphology, Gram stain, catalase test, and MASTASAPH Latex test). Parallel findings have been obtained in previous studies in Ethiopia (Getahun et al., 2007; Marama et al., 2016). A similar study, conducted in China, showed that the spread of S. aureus in the raw milk of cows was 22\% (Liu et al., 2017). In general, our present data show that $S$. aureus often exists in the raw milk of mastitis-infected animals in the Central Region of the Kingdom of KSA.

The quick and precise identification of $S$. aureus strains in cultures taken from samples of milk is the mainstay of governing $S$. aureus mastitis. The coagulase test, as a standard tool, has high sensitivity and has been used to identify the existence of $S$. aureus in milk samples. However, only half of the isolates were tested positive after incubation for $4 \mathrm{~h}$; incubation for a night is necessary to get accurate results (Dai et al., 2019). Thus, the commercial tools utilized to determine the existence of $S$. aureus are widely used in clinical microbiology laboratories, as the analysis of tubular coagulation, which is commonly used as an ideal index for S. aureus exploration, requires up to $24 \mathrm{~h}$ to obtain concluding test results (Zschock et al., 2004; Wang et al., 2018).

Another study was carried out by Gülmez-Sağlam et al. (2017) on 235 milk cows infected with mastitis; a large number of both $S$. aureus and CNS were isolated. The percentage of Staphylococcus species was $49.7 \%$ (117/235). Out of 117 Staphylococcus isolates, $63.24 \%$ (74/117) and 36.75\% (43/117) were identified as S. aureus CNS, respectively. In addition, a study conducted by Sevinti and Şahin (2009) on 79 samples of milk from cows with a history of clinical mastitis in Kars Province detected 23 S. aureus and 19 CNS isolates. In the same study, the tests were performed to isolate $S$. aureus from 100 cows suffering from clinical and subclinical mastitis. It was found that $48(48 \%)$ Staphylococcus species were isolated as 22 (46\%) CPS and 26 (54\%) CNS. In this study, $S$. aureus is the bacterium that was isolated at the highest rate among the bacterial agents causing mastitis. This seems to be in harmony with the isolation results of other studies. Such variations in the levels of $S$. aureus prevalence are due to the varied populations investigated by the executed methodologies in addition to other elements (Li et al., 2017; Wang et al., 2018).

Because dromedary camels are considered to be among the most important sources of milk and meat for citizens in KSA, the current study also studies the prevalence of $S$. aureus among camels afflicted with mastitis. As stated by Jilo et al. (2017), the spread and causes of mastitis in camels have been reported as varied according to the geographical area and herd management. In the current investigation, the spread of Staphylococcal mastitis in camels reported in this study is shown as low, i.e., $12 \%$ (12/100 milk samples), particularly as compared to the previous studies of Al-Juboori et al. (2013) and Al-Dughaym et al. (2015), which demonstrated spreading rates from $36 \%$ to $41 \%$. No clear-cut clarification of this relatively low spread of bacteria in camels is present in the current research. However, other factors, such as hygienic milking practices and a proper milking area, might contribute to this low rate. 
Moreover, our study found that $S$. aureus is the prominent organism isolated from sheep and goats suffering from mastitis, at $39.28 \%$ (11/28 isolates) in sheep and $43.75 \%$ $(14 / 32$ isolates) in goats. Similar studies supported this finding, i.e., Alemu and Abraha (2017); Abdalhamed et al. (2018); and Haggag et al. (2019), who revealed that S. aureus is the primary microorganism found in dairy goats because it is detected in ranges from $6 \%$ to $40 \%$ in all extracted microorganisms.

While Staphylococci consist of forty-five species and twenty-one subspecies that are known to be the key causes of mastitis in dairy animals, there is still debate over the clinical relevance of $S$. aureus isolated from animals infected with mastitis. Some regard S. aureus as a main carrier of mastitis, while others view it as a minor carrier of the disease (Harjanti et al., 2018). Thus, the present study examined seemingly healthy animals and others that presented symptoms of mastitis; $54 \mathrm{~S}$. aureus isolates and 66 CNS isolates were correctly recognized by using tube coagulase test and later by the Vitek $^{\text {TM }} 2$ compact system. The potential capability of the Vitek 2 system (ID-GPC card) to quickly and effectively identify Gram-positive cocci was initially evaluated by Basses et al. (1997), who revealed, via isolates of Staphylococci, Streptococci, and Enterococci, $98.0 \%$ total agreement $(86.8 \%$ agreement to the species level without supplemental testing needed and $11.2 \%$ agreement to the species level after additional testing), while $1.7 \%$ of isolates were not correctly identified and $0.3 \%$ of isolates were not identified (Ligozzi et al., 2002; Huh et al., 2018).

In the present study, similar accuracy rates were shown by the Vitek 2 system in the uncovering of Staphylococci. The organisms that showed less discrimination identification comprised a limited count of strains and did not provide important information regarding the improvement by Vitek 2 system. As per the results of the current study, correct identification of $51 / 54$ isolates of $S$. aureus (94\%) was achieved. Typical results were accessed by past researchers, such as Spanu et al. (2003), who evaluated the ability of the Vitek 2 system in rapidly identifying 130 S. aureus and 275 CNS strains extracted from blood cultures and demonstrated that $90.5 \%$ of CNS and $99.2 \%$ of S. aureus strains were suitably marked out.

Other studies examined eleven S. aureus isolates via the Vitek 2 system and reported that the species were 100\% identified (Da Silva Paim et al., 2014; Gitau et al., 2018). The Vitek 2 system contributed to the right identification of Grampositive microorganisms; however, this method did not manage to detect some uncommon bacteria due to certain restrictions. Consequently, an extra method must be used to precisely detect the bacteria at the species level (Elbehiry et al., 2016). The drawback of all the published research is the notion that the ID32 STAPH system is widely used as a comparative approach to evaluate the other systems of phenotypic identification, such as the Vitek 2 system (Layer et al., 2006; Ambaraghassi et al., 2019). Because the ID32 STAPH system is normally used as a reference approach, results attained with ID32 STAPH are added. In the study of El Behiry et al. (2014), 89\% of the tested S. aureus strains were correctly identified via the ID32 STAPH system, which matched our study, in which the ID32 STAPH system was able to correctly identify (84\%) (in all tests) the Staphylococcal species.

PMFT is one of powerful, fast, truthful, and correct technique of identifying microorganisms, especially in subclinical and clinical cases of mastitis (Carbonnelle et al., 2007; El Behiry et al., 2014; Elbehiry et al., 2016). The application of PMFT in the diagnosis of mastitis has been demonstrated by Nonnemann et al. (2018); it was shown to be a cost-effective and quick method when applied to 500 isolates, and twentyfour genera and sixty-one specifies were identified. In this research, the $S$. aureus strain was identified by proteomic analysis and the accuracy of identification at the levels of genus and species was 54/54 (100\%). Similar results were shown by Loonen et al. (2012), who found CNS isolates recovered from clinical cultures through 5 methods: tuf gene sequencing, 16S rRNA gene sequencing, Staph ID 32 API system, Vitek 2 system, and PMFT. Also, PMFT was found to be the method that delivered the highest rate of identification $(99.3 \%)$.

In this research, the data were analyzed by MBT, which revealed that the range of the majority of spectral peaks of the examined S. aureus strains was between 3,000-10,000 Da. This finding is consistent with the findings of several similar studies that addressed microbial detection through MBT (Lartigue et al., 2009; Barreiro et al., 2010; Silva et al., 2015). However, this range is comparable to those of previous studies, which revealed that the range of most of the peaks is from 800-3500 Da (Edwards-Jones et al., 2000; Walker et al., 2002). As concluded by Shell et al. (2017), on strains and isolates extracted from mastitis cases examined by MBT, the peaks ranged from 3,000 to $11,000 \mathrm{Da}$ and the highest levels of intensity ranged between 4,000 and 10,000 Da. Such variations in the spectral peaks, range, and mass can be attributed to differences in the arrangement of sampling approaches. Although their variations in spectra were based on the source, there is a continuing order for use of the PMFT method to diagnose new subareas through which to identify microbes such as fish pathogens, environmental microbial isolates, and mastitis pathogens (Nonnemann et al., 2018).

Also, this study aimed to identify the capability of PMFT to correctly differentiate between MRSA and MSSA. Many researchers investigated MBT typing profiles. Some researchers emphasized the connection between MBT profiles created by MSSA and MRSA. In a study by Du et al. (2002), 74\% of 76 $S$. aureus strains and MRSA were exactly identified from MSSA by utilizing cluster analysis together with a dendrogram. Jackson et al. (2005) revealed that MRSA and MSSA in S. aureus showed varied intensities at $\mathrm{m} / \mathrm{z} 3048, \mathrm{~m} / \mathrm{z} 3086$, and $\mathrm{m} / \mathrm{z}$ 3124. Furthermore, Drake et al. (2011) suggested differentiation based on peaks noticed at m/z 2302 and m/z 3871 . According to Tang et al. (2019), MSSA and MRSA can be differentiated by MBT with an accuracy of over $90 \%$. In this study, the chosen peaks at the masses of 2,636 Da and 3,009 Da granted robust emphasis to distinguish between MSSA and MRSA. The time required to obtain results from MBT was clearly less than that required by molecular approaches and methods.

The remarkable differences between classical identification techniques and PMFT are represented in the anticipated time and cost required to identify the sample. The cost of using PMFT to identify bacteria amounts to about $€ 1.43 /$ sample, but sample identification with other classical methods costs $€ 4.6-8.23 /$ sample (Feucherolles et al., 2019).

Moreover, Cherkaoui et al. (2010) demonstrated that the cost of the reagents required for phenotypic identification employing recent automated tools is approximately $\$ 10$ per isolate, but does not exceed 0.50 per sample with PMFT. The cost and maintenance expenses of PMFT are among the potential pitfalls of this technology (Neville et al., 2011; Chen et al., 2013; Pavlovic et al., 2013; Macori et al., 2019).

In this study, the PMFT technique is compared to the colorimetric method. The results showed that the use of PMFT to identify the different strains of Staphylococcus is a superior technique because it entails a simple procedure, a large sampling volume, premium accuracy, and higher 
sensitivity. Here, the $S$. aureus strains extracted from animals infected with mastitis were identified more quickly, economically, and precisely by MBT with compass software than by the Vitek 2 compact system and staph ID system. Also, MBT showed a better capability for discrimination between MRSA and MSSA in terms of peak intensities. Thus, the ability to solve the problems of mastitis, whether clinical or subclinical, was available when precise and early diagnostic tools were used.

The release of $\beta$-lactamase by $S$. aureus is the reason for the inability to treat subclinical mastitis using penicillin. This leads to hydrolysis of $\beta$-lactam rings. The majority of $S$. aureus strains release penicillinases, which then make $S$. aureus resistant to the $\beta$-lactam set of antibiotics (Algammal et al., 2020). The prominent feature notice for $S$. aureus is the resistance to $\beta$-lactam or aminoglycosides (Virdis et al., 2010). This is demonstrated in the current study, which elicited a resistance rate of $94 \%$ of the extracts toward carbenicillin of $\beta$-lactam group. This finding corresponds with the results of Zhang et al. (2012), who concluded a 90\% resistance grade to penicillin. In contrast, no resistance to aminoglycosides was noticed in this research based on $81 \%$ susceptibility for gentamicin. About $60 \%-90 \%$ of the microorganisms recovered from clinical and subclinical mastitis showed resistance to $\beta$-lactam antibiotics (Barboza-Corona et al., 2009; León-Galván et al., 2015). Typical results were found by Zhang and Buckling (2012), who reported that $94.8 \%$ of the isolates resisted at least one antimicrobial agent, especially penicillin and ampicillin. Also, the resistance rate of erythromycin (85.6\%) reported by Zhang et al. (2012) contradicts the results of the current study, which revealed a resistance rate of only $39 \%$.

The resistance of $S$. aureus to various antimicrobials goes back to the attainment of moving genetic elements including plasmids and jumping genetic elements (insertion sequences and transposons). Such elements integrate the determinants of antimicrobial resistance and move among species or stains through horizontal gene transfer. The first resistance to penicillin caused by the release of $\beta$-lactamase, and that caused hydrolysis of the $\beta$-lactam ring was found in the 1940s (Varela-Ortiz et al., 2018). According to Adzitey (2015) and Mansor et al. (2019), the resistance to antibiotics differs from one region to another and depends on many factors such as the time, the tested samples, the method of sampling, and the degree to which the antibiotics are used in different areas.

In conclusion, Successful management and planning to diagnose infectious mastitis in KSA requires an effective, robust, and accurate monitoring system for all dairy farms and flocks, together with rapid and exact identification of the microorganisms that cause this infection. The quick identification of microorganisms is achieved by PMFT, which takes about thirty minutes per isolate from the intended plate to obtain the ultimate results. Also, less effort is required to prepare the sample. In this research, PMFT is reported to be the most rapid and sensitive instrument by which to identify $S$. aureus isolates that cause infectious mastitis when it is benchmarked against other classical methods such as Vitek 2 and the ABI system. It was concluded that $S$. aureus bacteria are among the main microorganisms causing mastitis in KSA. PMFT is characterized by accuracy, quickness, and reliability. It could be used as a systematic tool to detect and distinguish $S$. aureus and mastitis-causing bacteria isolates in veterinary laboratories in KSA in order to accurately identify the clinical specimens. However, this assay requires more validation and verification utilizing more samples to determine the performance, reliability, specificity, and sensitivity of this kind of bacterial discrimination. $S$. aureus revealed a higher degree of resistance $(94.4 \%)$ to carbenicillin of the $\beta$-lactam group. In contrast, $94.44 \%$ and $81.48 \%$ of $S$. aureus strains were sensitive to clindamycin and gentamycin, respectively.

\section{ACKNOWLEDGEMENTS}

This research was made possible with the support of Qassim University, Kingdom of Saudi Arabia.

\section{Conflict of interest}

The authors declare that they have no competing interests.

\section{REFERENCES}

Abdalhamed, A.M., Zeedan, G.S.G. \& Abou Zeina, H.A.A. (2018). Isolation and identification of bacteria causing mastitis in small ruminants and their susceptibility to antibiotics, honey, essential oils, and plant extracts. Veterinary World 11: 355-362. https://doi.org/10.14202/vetworld.2018.355-362

Al-Dughaym, A.M. \& Fadlelmula, A. (2015). Prevalence, etiology and its seasonal prevalence of clinical and subclinical Camel Mastitis in Saudi Arabia. British Journal of Applied Science \& Technology 9: 441-449. https://doi.org/10.9734/ BJAST/2015/17593

Adzitey, F., Nafisah, S. \& Haruna, A. (2015). Antibiotic susceptibility of Escherichia coli isolated from some drinking water sources in Tamale Metropolis of Ghana. Current Research in Bacteriology 8: 34-40. https://doi.org/ 10.3923/crb.2015.34.40

Alemu, S. \& Abraha, A. (2017). Prevalence of bacteria associated with subclinical mastitis in Haramaya University dairy cattle, goat and sheep farms. East African Journal of Veterinary and Animal Sciences 1: 61-66.

Algammal, A.M., Enany, M.E., El-Tarabili, R.M., Ghobashy, M.O.I. \& Helmy, Y.A. (2020). Enterotoxins-Determinant Genes of MRSA isolated from subclinical bovine mastitis prevalence, antimicrobial resistance profiles, virulence and in Egypt. Pathogens 9: 362. https://doi.org/10.3390/ pathogens 9050362

Al-Juboori, A.A., Kamat, N.K. \& Sindhu, J.I. (2013). Prevalence of some mastitis causes in dromedary camels in Abu Dhabi, United Arab Emirates. Iraqi Journal of Veterinary Sciences 27: 9-14. https://doi.org/10.33899/ijvs.2013.82861

Ambaraghassi, G., Dufresne, P.J., Dufresne, S.F., Vallières, É., Muñoz, J.F., Cuomo, C.A., Berkow, E.L., Lockhart, S.R. \& Luong, M.L. (2019). Identification of Candida auris by use of the updated Vitek 2 Yeast Identification System, Version 8.01: a multilaboratory evaluation study. Journal of Clinical Microbiology 57: e00884-19. https://doi.org/10.1128/JCM. 00884-19

Barboza-Corona, J.E., de la Fuente-Salcido, N., Alva-Murillo, N., Ochoa-Zarzosa, A. \& Lopez-Meza, J.E. (2009). Activity of bacteriocins synthesized by Bacillus thuringiensis against Staphylococcus aureus isolates associated to bovine mastitis. Veterinary Microbiology 138: 179-183. https://doi. org/10.1016/j.vetmic.2009.03.018

Barlow, M. (2009). What antimicrobial resistance has taught us about horizontal gene transfer. Methods in Molecular Biology 532: 397-411. https://doi.org/10.1007/978-1-60327853-9_23

Barreiro, J.R., Ferreira, C.R., Sanvido, G.B., Kostrzewa, M., Maier, T., Wegemann, B., Böttcher, V., Eberlin, M.N. \& Santos, M.V. (2010). Identification of subclinical cow mastitis pathogens in milk by matrix-assisted laser desorption/ ionization time of-flight mass spectrometry. Journal of Dairy Science 93: 5661-5667. https://doi.org/10.3168/jds.2010-3614 
Barreiro, J.R., Goncalves, J.L., Grenfall, R., Leite, R.F., Juliano, L. \& Santos, M.V. (2018). Direct identification of bovine mastitis pathogens by matrix-assisted laser desorption/ ionization time-of-flight mass spectrometry in preincubated milk. Brazilian Journal of Mycology 49: 801-807. https://doi.org/10.1016/j.bjm.2018.04.012

Basanisi, M.G., La Bella, G., Nobili, G., Franconieri, I. \& La Salandra, G. (2017). Genotyping of methicillin-resistant Staphylococcus aureus (MRSA) isolated from milk and dairy products in South Italy. Food Microbiology 62: 141-146. https://doi.org/10.1016/j.fm.2016.10.020

Basdew, I.H. \& Laing, M.D. (2011). Biological control of bovine mastitis using bacteriophage therapy. In: Science Against Microbial Pathogens: Communicating Current Research and Technological Advances, Méndez-Vilas, A. (editor). Badajoz: Formatex Research Centre, pp. 386-393.

Bizzini, A., Durussel, C., Bille, J., Greub, G. \& Prod'hom, G. (2010). Performance of matrix-assisted laser desorption ionization-time of flight mass spectrometry for identification of bacterial strains routinely isolated in a clinical microbiology laboratory. Journal of Clinical Microbiology 48: 1549-1554. https://doi.org/10.1128/JCM.01794-09

Böhme, K., Morandi, S., Cremonesi, P., Fernández, N.C., Barros Velázquez, J., Castiglioni, B. \& Calo-Mata, P. (2012). Characterization of Staphylococcus aureus strains isolated from Italian dairy products by MALDI- TOF mass fingerprinting. Electrophoresis 33: 2355-2364. https://doi.org/ 10.1002/elps.201100480

Burckhardt, I. \& Zimmermann, S. (2011). Using Matrix-Assisted Laser Desorption Ionization-Time of Flight Mass Spectrometry to detect carbapenem resistance within 1 to 2.5 hours. Journal of Clinical Microbiology 49: 3321-3324. https://doi.org/10.1128/JCM.00287-11

Carbonnelle, E., Beretti, J.L., Cottyn, S., Quesne, G., Berche, P., Nassif, X. \& Ferroni, A. (2007). Rapid identification of Staphylococci isolated in clinical microbiology laboratories by matrix-assisted laser desorption ionizationtime of flight mass spectrometry. Journal of Clinical Microbiology 45: 2156-2161. https://doi.org/10.1128/ JCM.02405-06

Chen, Y.L., Lin, Y.C., Chen, Y.S., Chen, S.C., Liu, Y.M. \& Tseng, I.L. (2013). Characterization of predominant molecular patterns of Burkholderia pseudomallei in Taiwan. Transactions of the Royal Society of Tropical Medicine and Hygiene 107: 165169. https://doi.org/10.1093/trstmh/trs093

Cherkaoui, A., Emonet, S., Fernandez, J., Schorderet, D. \& Schrenzel, J. (2011). Evaluation of matrix-assisted laser desorption ionization-time of flight mass spectrometry for rapid identification of beta-hemolytic Streptococci. Journal of Clinical Microbiology 49: 3004-3005. https://doi.org/ 10.1128/JCM.00240-11

Cherkaoui, A., Hibbs, J., Emonet, S., Tangomo, M., Girard, M., Francois, P. \& Schrenzel, J. (2010). Comparison of two matrix-assisted laser desorption ionization-time of flight mass spectrometry methods with conventional phenotypic identification for routine identification of bacteria to the species level. Journal of Clinical Microbiology 48: 1169-1175. https://doi.org/10.1128/JCM.01881-09

Clinical and Laboratory Standards Institute (CLSI). (2009). Performance standards for antimicrobial susceptibility testing: Nineteenth informational supplement, M100-S19, CLSI, Wayne, PA.

Clinical and Laboratory Standards Institute (CLSI). (2016). Performance standards for antimicrobial susceptibility testing; Twentieth informational supplement CLSI document M100-S20. Wayne.
Da Silva Paim, T.G., Cantarelli, V.V. \& d'Azevedo, P.A. (2014). Performance of the Vitek 2 system software version 5.03 in the bacterial identification and antimicrobial susceptibility test: evaluation study of clinical and reference strains of Gram-positive cocci. Revista da Sociedade Brasileira de Medicina Tropical 47: 377-381. https://doi.org/10.1590/0037-8682-0123-2013

Dai, J., Wu, S., Huang, J., Wu, Q., Zhang, F., Zhang, J., Wang, J., Ding, Y., Zhang, S. \& Yang, X. (2019). Prevalence and characterization of Staphylococcus aureus isolated from pasteurized milk in China. Frontiers in Microbiology 10: 641. https://doi.org/10.3389/fmicb.2019.00641

Deb, R., Kumar, A., Chakraborty, S., Verma, A.K., Tiwari, R., Dhama, K., Singh, U. \& Kumar, S. (2013). Trends in diagnosis and control of bovine mastitis: a review. Pakistan Journal of Biological Sciences 16: 1653-1661. https://doi.org/10.3923/ pjbs.2013.1653.1661

Drake, R.R., Boggs, S.R. \& Drake, S.K. (2011). Pathogen identification using mass spectrometry in the clinical microbiology laboratory. Journal of Mass Spectrometry 12: 32-46. https://doi.org/10.1002/jms.2008

Du, Z., Yang, R., Guo, Z., Song, Y. \& Wang, J. (2002). Identification of Staphylococcus aureus and determination of its methicillin resistance by matrix- assisted laser desorption/ionization time- of- flight mass spectrometry. Analytical Chemistry 74: 5487-5491. https://doi.org/10.1021/ ac020109k

Edwards-Jones, V., Claydon, M.A., Evason, D.J., Walker, J., Fox, A.J. \& Gordon, D.B. (2000). Rapid discrimination between methicillin sensitive and methicillin-resistant Staphylo coccus aureus by intact cell mass spectrometry. Journal of Medical Microbiology 49: 295-300. https://doi.org/10.1099/ 0022-1317-49-3-295

El Behiry, A., Schlenker, G., Szabo, I. \& Roesler, U. (2012). In vitro susceptibility of Staphylococcus aureus strains isolated from cows with subclinical mastitis to different antimicrobial agents. Journal of Veterinary Science 13: 153-161. https://doi.org/10.4142/jvs.2012.13.2.153

El Behiry, A., Zahran, R.N., Marzouk, E. \& Al-Dabib, M. (2014). Phenotypical and mass spectral assessment methods for identification of some contagious mastitis pathogens. American Journal of Microbiology 5: 1-10. https://doi.org/ 10.3844/ajmsp.2014.1.10

Elbehiry, A., Al-Dubaib, M., Marzouk, E., Osman, S. \& Edrees, H. (2016). Performance of MALDI biotyper compared with Vitek $^{\mathrm{TM}} 2$ compact system for fast identification and discrimination of Staphylococcus species isolated from bovine mastitis. MicrobiologyOpen 5: 1061-1070. https:// doi.org/10.1002/mbo3.389

Emonet, S., Shah, H.N., Cherkaoui, A. \& Schrenzel, J. (2010). Application and use of various mass spectrometry methods in clinical microbiology. Clinical Microbiology and Infection 16: 1604-1613. https://doi.org/10.1111/j.14690691.2010.03368.x

Feucherolles, M., Cauchie, H.M. \& Penny, C. (2019). MALDI-TOF mass spectrometry and specific biomarkers: Potential new key for swift identification of antimicrobial resistance in foodborne pathogens. Microorganisms 7: 593. https://doi. org $/ 10.3390 /$ microorganisms7120593

Getahun, K., Kelay, B., Bekana, M. \& Lobago, F. (2007). Bovine mastitis and antibiotic resistance patterns in Selalle smallholder dairy farms, central Ethiopia. Tropical Animal Health and Production 40: 261-268. https://doi.org/10.1007/ s11250-007-9090-5 
Gitau, W., Masika, M., Musyoki, M., Museve, B. \& Mutwiri, T. (2018). Antimicrobial susceptibility pattern of Staphylococcus aureus isolates from clinical specimens at Kenyatta National Hospital. BMC Research Notes 11: 226. https:// doi.org/10.1186/s13104-018-3337-2

Goudarzi, M., Kobayashi, N., Dadashi, M., Pantůček, R., Nasiri, M.J., Fazeli, M., Pouriran, R., Goudarzi, H., Miri, M. \& Amirpour, A. (2020). Prevalence, genetic diversity, and temporary shifts of inducible clindamycin resistance Staphylococcus aureus clones in Tehran, Iran: A molecularepidemiological analysis from 2013 to 2018. Frontiers in Microbiology 11: 663. https://doi.org/10.3389/ fmicb.2020. 00663

Guimarães, F.F., Manzi, M.P., Joaquim, S.F., Richini-Pereira, V.B. \& Langoni, H. (2017). Outbreak of methicillin-resistant Staphylococcus aureus (MRSA)-associated mastitis in a closed dairy herd. Journal of Dairy Science 100: 726-730. https://doi.org/10.3168/jds.2016-11700

Guimarães, F.F., Nóbrega, D.B., Richini-Pereira, V.B., Marson, P.M., Pantoja, J.C.F. \& Langoni, H. (2013). Enterotoxin genes in coagulase negative and coagulase-positive staphylococci isolated from bovine milk. Journal of Dairy Science 96: 2866-2872. https://doi.org/10.3168/jds.2012-5864

Gülmez-Sağlam, A., Şahin, M., Çelik, E., Çelebi, O., Akça, D. \& Otlu, S. (2017). The role of staphylococci in subclinical mastitis of cows and lytic phage isolation against to Staphylococcus aureus. Veterinary World 10: 1481-1485. https://doi.org/10.14202/vetworld.2017.1481-1485

Haggag, Y.N., Nossair, M.A., Habib, H.M., El Naggar, A.L., Abdallah, M. \& Farag, H.E. (2019). Prevalence of Subclinical Mastitis in Small Ruminants and Role of Staphylococcus Species in Such Infection. Alexandria Journal for Veterinary Sciences 62: 64-71. https://doi.org/10.5455/ajvs.57952

Han, H.W., Chang, H.C., Hunag, A.H. \& Chang, T.C. (2015). Optimization of the score cutoff value for routine identification of Staphylococcus species by matrixassisted laser desorption ionization-time-of-flight mass spectrometry. Diagnostic Microbiology and Infectious Disease 83: 349-354. https://doi.org/10.1016/j.diagmicrobio.2015. 08.003

Harjanti, D.W., Ciptaningtyas, R., Wahyono, F. \& Setiatin, E.T. (2018). Isolation and identification of bacterial pathogen from mastitis milk in Central Java Indonesia. Earth and Environmental Science 102: 1-6. https://doi.org/10.1088/17551315/102/1/012076

Hendriksen, R.S., Mevius, D.J., Schroeter, A., Teale, C., Meunier, D., Butaye, P., Franco, A., Utinane, A., Amado, A. \& Moreno, M. (2008). Prevalence of antimicrobial resistance among bacterial pathogens isolated from cattle in different European countries: 2002-2004. Acta Veterinaria Scandinavica 50: 28. https://doi.org/10.1186/1751-0147-50-28

Huh, H.J., Song, D.J., Shim, H.J., Kwon, W.K., Park, M.S., Ryu, M.R. \& Lee, N.Y. (2018). Performance evaluation of the QMACdRAST for staphylococci and enterococci isolated from blood culture: a comparative study of performance with the VITEK-2 system. Journal of Antimicrobial Chemotherapy 73: 1267-1271. p https://doi.org/10.1093/jac/dky015

Jackson, K.A., Edwards-Jones, V., Sutton, C.W. \& Fox, A.J. (2005). Optimization of intact cell MALDI method for fingerprinting of methicillin-resistant Staphylococcus aureus. Journal of Microbiological Methods 3: 62-84. https:// doi.org/10.1016/j.mimet.2005.04.015

Jilo, K., Galgalo, W. \& Mata, W. (2017). Camel Mastitis: A Review. MOJ Ecology \& Environmental Sciences 2: 00034. https://doi.org/10.15406/mojes.2017.02.00034
Koivula, M., Mäntysaari, E.A., Pitkälä, A. \& Pyörälä, S. (2007). Distribution of bacteria and seasonal and regional effects in a new database for mastitis pathogens in Finland. Acta Agriculturae Scandinavica, Section A - Animal Science 57: 89-96. https://doi.org/10.1080/09064700701488941

Lartigue, M.F., Héry-Arnaud, G., Haguenoer, E., Domelier, A.S., Schmit, P.O., van der Mee-Marquet, N. \& Quentin, R. (2009). Identification of Streptococcus agalactiae isolates from various phylogenetic lineages by matrix-assisted laser desorption ionization-time of flight mass spectrometry. Journal of Clinical Microbiology 47: 2284-2287. https://doi. org/10.1128/JCM.00175-09

Layer, F., Ghebremedhin, B., Moder, K.A., Ko"nig, W. \& Ko"nig, B. (2006). Comparative study using various methods for identification of Staphylococcus species in clinical specimens. Journal of Clinical Microbiology 44: 2824-2830. https://doi.org/10.1128/JCM.00226-06

León-Galván, M.F., Barboza-Corona, J.E., Lechuga-Arana, A.A., ValenciaPosadas, M., Aguayo, D.D., Cedillo-Pelaez, C., Martínez-Ortega, E.A. \& Gutierrez-Chavez, A.J. (2015). Molecular detection and sensitivity to antibiotics and bacteriocins of pathogens isolates from bovine mastitis in family dairy herds of central Mexico. BioMed Research International 615153. https://doi.org/10.1155/2015/615153

Li, T., Lu, H., Wang, X., Gao, Q., Dai, Y., Shang, J. \& Li, M. (2017). Molecular characteristics of Staphylococcus aureus causing bovine mastitis between 2014 and 2015. Frontiers in Cellular and Infection Microbiology 7: 127. https://doi.org/10.3389/ fcimb.2017.00127

Ligozzi, M., Bernini, C., Bonora, M.G., Fatima, M.D., Zuliani, J. \& Fontana, R. (2002). Evaluation of the VITEK 2 system for identification and antimicrobial susceptibility testing of medically relevant gram-positive Cocci. Journal of Clinical Microbiology 40: 1681-1686. https://doi.org/10.1128/ jcm.40.5.1681-1686.2002

Liu, H., Li, S., Meng, L., Dong, L., Zhao, S., Lan, X., Wang, J. \& Zheng, N. (2017). Prevalence, antimicrobial susceptibility, and molecular characterization of Staphylococcus aureus isolated from dairy herds in northern China. Journal of Dairy Science 100: 8796-8803. https://doi.org/10.3168/ jds.2017-13370

Loonen, A.J., Jansz, A.R., Bergland, J.N., Valkenburg, M., Wolffs, P.F. \& van den Brule, A.J. (2012). Comparative study using phenotypic, genotypic, and proteomics methods for identification of coagulase-negative staphylococci. Journal of Clinical Microbiology 50: 1437-1439. https://doi.org/ 10.1128/JCM.06746-11

Luther, M.K., Parente, D.M., Caffrey, A.R., Daffinee, K.E., Lopes, V.V., Martin, E.T. \& LaPlante, K.L. (2018). Clinical and Genetic Risk Factors for Biofilm-Forming Staphylococcus aureus. Antimicrobial Agents and Chemotherapy 62: e02252-17. https://doi.org/10.1128/AAC.02252-17

Macfaddin, J.F. (2000). Biochemical Tests for Identification of Medical Bacteria. 3rd Edition. USA: Lippincott Williams and Wilkins USA.

Macori, G., Bellio, A., Bianchi, D.M., Chiesa, F., Gallina, S., Romano, A., Zuccon, F., Cabrera-Rubio, R., Cauquil, A. \& Merda, D. (2019). Genome-wide profiling of enterotoxigenic Staphylococcus aureus strains used for the production of naturally contaminated cheeses. Genes 11: 33. https://doi.org/10.3390/genes 11010033

Mansor, R., Diauudin, N.S., Syed-Hussain, S.S. \& Khalid, S.F. (2019). Antibiotic susceptibility of Staphylococcus aureus and Escherichia coli isolated from dairy goats in selected farms in Selangor, Malaysia. Jurnal Veterinar Malaysia 31: 12-16. 
Marama, A., Mamu, G. \& Birhanu, T. (2016). Prevalence and antibiotic resistance of Staphylococcus aureus mastitis in Holeta Area, Western Ethiopia. Global Veterinaria 4: 365370.

Miller, L.S., Fowler, V.G., Shukla, S.K., Rose, W.E. \& Proctor, R.A. (2020). Development of a vaccine against Staphylococcus aureus invasive infections: Evidence based on human immunity, genetics and bacterial evasion mechanisms. FEMS Microbiology Reviews 44: 123-153. https://doi.org/ $10.1093 /$ femsre/fuz030

National Mastitis Council (2001). Summary of peer-reviewed publications on efficacy of premilking and postmilking teat disinfectants published since 1980. Annual Meeting - National Mastitis Council, Inc., 1996: 245-256.

Neville, S.A., Lecordier, A., Ziochos, H., Chater, M.J., Gosbell, I.B., Maley, M.W. \& van Hal, S.J. (2011). Utility of matrix assisted laser desorption/ionization time-of-flight mass spectrometry (MALDI-TOF MS) following introduction for routine laboratory bacterial identification. Journal of Clinical Microbiology 49: 2980-2984. https://doi.org/10.1128/ JCM.00431-11

Nonnemann, B., Lyhs, U., Svennesen, L., Kristensen, K.A., Klaas, L.C. \& Pedersen, K. (2018). Bovine mastitis bacteria resolved by MALDI TOF mass spectrometry. Journal of Dairy Science 102: 2515-2524. https://doi.org/10.3168/jds.201815424

Pavlovic, M., Huber, I., Konrad, R. \& Busch, U. (2013). Application of MALDITOF MS for the identification of food borne bacteria. Open Microbiology Journal 7: 135-141. https:// doi.org/10.2174/1874285801307010135

Pollitt, E., Szkuta, P.T., Burns, N. \& Foster, S.J. (2018). Staphylococcus aureus infection dynamics. PLoS Pathogens 14: e1007112. https://doi.org/10.1371/journal.ppat.1007112

Pumipuntu, N., Tunyong, W., Chantratita, N., Diraphat, P., Pumirat, P., Sookrung, N., Chaicumpa, W. \& Indrawattana, N. (2019). Staphylococcus spp. associated with subclinical bovine mastitis in central and northeast provinces of Thailand. Peer Journal 7: e6587. https://doi.org/10.7717/ peerj. 6587

Quinn, J., Carter, E., Markey, B. \& Carter, R. (1999). Mastitis in Clinical Veterinary Microbiology. London: Mosby International Limited, pp. 327-344.

Rollin, E., Dhuyvetter, K.C. \& Overton, M.W. (2015). The cost of clinical mastitis in the first 30 days of lactation: an economic modeling tool. Preventive Veterinary Medicine 122: 254-264. https://doi.org/10.1016/j.prevetmed.2015.11.006

Sağlam, A.G., Şahin, M., Çelik, E., Çelebi, O., Akça, D. \& Otlu, S. (2017). The role of staphylococci in subclinical mastitis of cows and lytic phage isolation against to Staphylococcus aureus. Veterinary World 10: 1481-1485. https://doi.org/ 10.14202/vetworld.2017.1481-1485

Sampimon, O.C., Zadoks, R.N., Vliegher, S. De, Supre, K., Haesebrouck, F., Barkema, H.W., Sol, J. \& Lam, T.J. (2009). Performance of API Staph ID 32 and Staph-Zym for identification of coagulase-negative staphylococci isolated from bovine milk samples. Veterinary Microbiology 136: 300-305. https://doi.org/10.1016/j.vetmic.2008.11.004

Sauer, S., Freiwald, A., Maier, T.H., Kube, M., Reinhardt, R., Kostrzewa, M. \& Geider, K. (2008). Classification and identification of bacteria by mass spectrometry and computational analysis. PLOS ONE 3: e2843. https://doi. org/10.1371/journal.pone.0002843
Schröttner, P., Rudolph, W.W., Eing, B.R., Bertram, S. \& Gunzer, F. (2014). Comparison of VITEK2, MALDI-TOF MS, and 16S rDNA sequencing for identification of Myroides odoratus and Myroides odoratimimus. Diagnostic Microbiology and Infectious Disease 79: 155-159. https://doi.org/10.1016/ j.diagmicrobio.2014.02.002

Sender, G., Pawlik, A. \& Korwin-Kossakowska, A. (2017). Current concepts on the impact of coagulase-negative staphylococci causing bovine mastitis as a threat to human and animal health - a review. Animal Science Papers and Reports 35: 123-135.

Sevinti, D.A. \& Şahin, M. (2009). Determination of beta-lactic activity and susceptibility of against some antibiotics staphylococci strains isolated from bovine mastitis. Veteriner Bilimleri Dergisi 25: 23-28.

Shell, W.S., Sayed, M.L., El-Gedawy, A.A., El Sadek, G.M., Samy, A.A. \& Ali, M.M. (2017). Identification of Staphylococcus aureus causing bovine mastitis using MALDI-TOF fingerprinting. International Journal of Dairy Science 12: 105-113. https://doi.org/10.3923/ijds.2017.105.113

Silva, M.B., Ferreira, F., Garcia, L.N., Silva-Carvalho, M.C., Botelho, L.A., Figueiredo, A.M. \& Vieira-da-Motta, O. (2015). An evaluation of matrix assisted laser desorption ionization time-of-flight mass spectrometry for the identification of Staphylococcus pseudintermedius isolates from canine infections. Journal of Veterinary Diagnostic Investigation 27: 231-235. https://doi.org/10.1177/1040638 715573297

Spanu, T., Maurizio, S., Daniela, C., Tiziana, D., Lucio, R., Fiammetta, L. \& Giovanni, F. (2003). Use of the VITEK 2 system for rapid identification of clinical isolates of Staphylococci from bloodstream infections. Journal of Clinical Microbiology 41: 4259-4263. https://doi.org/10.1128/ jcm.41.9.4259-4263.2003

Sun, Y., Guo, J., Chen, R., Hu, L., Xia, Q., Wu, W. \& Hu, F. (2020). Multicenter evaluation of three different MALDI-TOF MS systems for identification of clinically relevant filamentous fungi. Medical Mycology 59: 81-86. https://doi.org/ $10.1093 / \mathrm{mmy} / \mathrm{myaa037}$

Tang, W., Ranganathan, N., Shahrezaei, V. \& Larrouy-Maumus, G. (2019). MALDI-TOF mass spectrometry on intact bacteria combined with a refined analysis framework allows accurate classification of MSSA and MRSA. PIOS ONE 14: e0218951. https://doi.org/10.1371/journal.pone.0218951

Taponen, S., Supré, K., Piessens, V., Van Coillie, E., DeVliedher, S. \& Koort, J.M.K. (2012). Staphylococcus agnetis sp. nov., a coagulase variable species from bovine subclinical and mild clinical mastitis. International Journal of Systematic and Evolutionary Microbiology 62: 61-65. https://doi.org/ 10.1099/ijs.0.028365-0

Varela-Ortiz, D.F., Barboza-Corona, J.E., González-Marrero, J., León-Galván, M.F., Valencia-Posadas, M., Lechuga-Arana, A.A., Sánchez-Felipe, C.G., Ledezma-García, F. \& GutiérrezChávez, A.G. (2018). Antibiotic susceptibility of Staphylococcus aureus isolated from subclinical bovine mastitis cases and in vitro efficacy of bacteriophage. Veterinary Research Communications 42: 243-250. https://doi.org/ 10.1007/s11259-018-9730-4

Virdis, S., Scarano, C., Cossu, F., Spanu, V., Spanu, C., Pietro, E. \& Santis, E.P.L.D. (2010). Antibiotic Resistance in Staphylococcus aureus and coagulase negative Staphylococci isolated from goats with subclinical mastitis. Veterinary Medicine International 2010: 1-6. https://doi.org/10.4061/ 2010/517060 
Walker, J., Fox, A.J., Edwards-Jones, V. \& Gordon, D.B. (2002). Intact cell mass spectrometry (ICMS) used to type methicillin resistant Staphylococcus aureus: media effects and inter-laboratory reproducibility. Journal of Microbiological Methods 48: 117-126. https://doi.org/10.1016/ s0167-7012(01)00316-5

Wang, W., Lin, X., Jiang, T., Peng, Z., Xu, J., Yi, L., Li, F., Fanning, S. \& Baloch, Z. (2018). Prevalence and Characterization of Staphylococcus aureus cultured From Raw Milk Taken from Dairy Cows with Mastitis in Beijing, China. Frontiers in Microbiology 9: 1123. https://doi.org/10.3389/fmicb.2018. 01123

Wang, Y.R., Chen, Q., Cui, S.H. \& Li, F.Q. (2013). Characterization of Staphylococcus aureus isolated from clinical specimens by matrix assisted lasser desorption/ionization time of flight mass spectrometry. Biomedical and Environmental Sciences 26: 430-436. https://doi.org/10.3967/0895-3988. 2013.06.003

Wolters, M., Rohde, H., Maier, T., Belmar-Campos, C., Franke, G., Scherpe, S., Aepfelbacher, M. \& Christner, M. (2010). MALDI-TOF MS fingerprinting allows for discrimination of major methicillin- resistant Staphylococcus aureus lineages. International Journal of Medical Microbiology 30: 64-68. https://doi.org/10.1016/j.ijmm.2010.06.002
Yan, W., Qian, J., Ge, Y., Ye, K., Zhou, C. \& Zhang, H. (2020). Principal component analysis of MALDI-TOF MS of wholecell foodborne pathogenic bacteria. Analytical Biochemistry 592: 113582. https://doi.org/10.1016/j.ab.2020.113582

Zecconi, A. \& Scali, F. (2013). Staphylococcus aureus virulence factors in evasion from innate immune defenses in human and animal diseases. Immunology Letters 150: 1222. https://doi.org/10.1016/j.imlet.2013.01.004

Zhang, C., Song, L., Chen, H., Lu, Y., Qin, Y. \& Ning, Y. (2012). Antimicrobial susceptibility and molecular subtypes of Staphylococcus aureus isolated from pig tonsils and cow's milk in China. Canadian Journal of Veterinary Research 76: 268-274.

Zhang, Q.G. \& Buckling, A. (2012). Phages limit the evolution of bacterial antibiotic resistance in experimental microcosms. Evolutionary Applications 5: 575-582. https://doi.org/ 10.1111/j.1752-4571.2011.00236.x

Zschock, M., Nesseler, A. \& Sudarwanto, I. (2004). Evaluation of six commercial identification kits for the identification of Staphylococcus aureus isolated from bovine mastitis. Journal of Applied Microbiology 98: 450-455. https://doi.org/ 10.1111/j.1365-2672.2004.02470.x 